\title{
DERMATOPATÍAS BACTERIANAS DE IMPORTANCIA EN MEDICINA EQUINA
}

\author{
Christian Tuemmers ${ }^{*} \&$ Angélica Saldivia \\ Universidad Católica de Temuco, Facultad de Recursos Naturales, Escuela de Medicina Veterinaria, Casilla \\ 15-D, Temuco, Chile. \\ *Autor para correspondencia: ctuemmers@uct.cl
}

Resumen

La dermatología representa una parte importante en la práctica equina. Las dermatopatías bacterianas comúnmente son causadas por patógenos oportunistas que son parte de la flora normal de la piel, que ingresan mediante disrupciones de la piel provocando el desarrollo de enfermedades; existen también patógenos que pueden provocar enfermedad sistémica que tienen manifestaciones cutáneas. Para el diagnóstico de las patologías cutáneas provocadas por bacterias es necesario realizar el examen clínico general y luego hacer un examen específico de la piel describiendo las características de la piel y las lesiones que se presentan. Hay numerosos métodos complementarios que ayudan a la identificación del agente etiológico; con el fin de instaurar el tratamiento adecuado. En nuestro país se han realizado pocos reportes y publicaciones respecto de las patologías cutáneas que afectan a los equinos, a su vez también es poca la variedad de antimicrobianos de uso en la clínica equina lo que impide el correcto tratamiento de las diferentes dermatopatías.

Palabras clave: dermatopatía, equinos, examen clínico, antibioticoterapia.

Summary

Dermatology represents an important part of equine practice. Bacterial skin diseases are commonly caused by opportunistic pathogens that are part of the normal flora of the skin, entering through the skin causing disruptions disease development; There are also pathogens that can cause systemic disease with skin manifestations. For the diagnosis of skin diseases caused by bacteria it is necessary to perform the clinical examination and then make a specific skin exam describing the characteristics of the skin and injuries that occur. There are numerous complementary methods that help the agent identification; in order to establish the appropriate treatment. In our country there have been few reports and publications regarding skin diseases affecting horses in turn is little variety of antimicrobial use in the equine clinic which prevents the correct treatment of various skin diseases.

Keywords: skin disease, equine, clinical examination, antibiotic therapy.

Introducción

La dermatología constituye una parte importante del trabajo del Médico Veterinario, ya que la piel es el primer elemento que el profesional veterinario observa en el animal al enfrentarse a él por primera vez y sobre todo porque desde el punto de vista clínico la piel tiene una enorme importancia (Ruiz, 2005).

Las enfermedades de la piel pueden afectar adversamente el valor de un caballo alterando su apariencia o interfiriendo con su rendimiento. Algunas dermatosis son el reflejo cutáneo de un problema metabólico subyacente o enfermedad interna. Muchas dermatosis son contagiosas, y unas pocas son zoonóticas. Un profundo conocimiento de las dermatosis que afectan a los caballos es un prerrequisito para el diagnóstico y tratamiento (Kobluk et al., 1995).

Dentro de las dermatosis del caballo encontramos varias etiologías o factores predisponentes, las cuales incluyen las patologías causadas por bacterias. Las enfermedades bacterianas de piel son causadas comúnmente por Staphylococcus, Corynebacterium pseudotuberculosis, Dermatophilus congolensis (Colahan et al., 1998), Actynomices spp, Brucella abortus; entre otros. Los signos clínicos más comunes asociados a infecciones bacterianas de la piel son costras, pápulas, abscesos, y zonas de drenaje; las últimas dos lesiones se asocian más comúnmente a $C$. pseudotuberculosis. Idealmente, el tratamiento antibiótico se debe basar en el cultivo y sensibilidad bacteriana (Kobluk et al., 1995). También es importante para el diagnóstico y tratamiento de las diferentes dermatopatías causadas por bacterias realizar una adecuada exploración 
clínica basada en el uso correcto de exámenes complementarios y el conocimiento de la historia del animal, datos que deben ser analizados de manera correcta para llegar a un diagnóstico certero y con ello realizar el tratamiento antimicrobiano más efectivo.

Anatomía macroscópica

Anatomía de la piel.

En términos de masa, la piel es el órgano más grande del cuerpo y se continúa con la membrana mucosa de las aberturas naturales del cuerpo (Colahan et al., 1998).

El espesor de la piel varía entre 1 y $5 \mathrm{~mm}$, dependiendo del lugar del cuerpo. La piel tiene mayor espesor en la frente, en la zona dorsal del cuello, en la dorsal del tórax y en la base de la cola (Reed et al., 2005). Las áreas de menor espesor cutáneo son el pabellón auricular, la axila y las regiones inguinal y perianal (Colahan et al., 1998).

Anatomía microscópica

La piel recubre la superficie del cuerpo y está constituida por una parte epitelial, de origen ectodérmico, la epidermis, y por una parte conjuntiva, de origen mesodérmico, la dermis. Por debajo y en continuidad con la dermis está la hipodermis que, aunque tenga el mismo origen que la dermis, no forma parte de la piel y sólo le sirve de soporte y unión con los órganos subyacentes (Junqueira \& Carneiro, 2000). El tejido subcutáneo (hipodermis) se analizará con la piel, ya que ciertas enfermedades de ésta involucran el tejido subcutáneo y viceversa.

- Epidermis: La epidermis es la capa más superficial de la piel; por medio de la microscopia de luz la epidermis puede dividirse en varios estratos, según la morfología de las células epiteliales (Colahan et al., 1998).

La capa más profunda de la epidermis, el estrato basal, está constituido por células prismáticas o cuboides que descansan sobre una lámina basal que separa la epidermis de la dermis. Esta capa, que contiene las células madre de la epidermis, se llama también germinativa (Junqueira y Carneiro, 2000). Las células del estrato basal tienen baja actividad mitótica y contienen citoplasma basófilo y un núcleo grande. En la zona lateral de la membrana celular se localizan muchos desmosomas que unen las células del estrato basal entre si y con células del estrato espinoso. Basalmente se localizan desmosomas que unen las células a la lámina basal (Gartner, 2002).

En el estrato basal son comunes las figuras mitóticas porque esta capa es la que se encarga en parte de la renovación de células en el epitelio (Gartner \& Hiatt, 2002).

El siguiente nivel, directamente producido por la división de las células basales, consiste en varios estratos de células (Colahan et al., 1998). Está constituido por células poligonales cuboidales o ligeramente aplanadas, de núcleo central con pequeñas expansiones citoplasmáticas que contienen tonofibrillas que parten de cada una de las células adyacentes. Estas expansiones citoplasmáticas se aproximan y se mantienen unidas mediante los desmosomas, lo que proporciona a la célula un aspecto espinoso (Junqueira \& Carneiro, 2000). El estrato espinoso consta de 2 a 4 capas. Las células van sufriendo una diferenciación progresiva a medida que se mueven hacia la parte externa del estrato y hacia la superficie de la piel (Reed et al., 2005). Los queratinocitos localizados basalmente en el estrato espinoso también tienen actividad mitótica y tienen a su cargo el recambio de queratinocitos de la epidermis (Gartner \& Hiatt, 2002).

El estrato granuloso es de presentación variable, dependiendo de si la piel tiene pelo mínimo, ausente o prominente (Colahan et al., 1998). Consiste en tres a cinco capas. Es la capa más superficial de la epidermis en la que las células aún tienen núcleo (Gartner \& Hiatt, 2002). Caracterizado por la presencia de células poligonales achatadas con núcleo central, en cuyo citoplasma se observan gránulos gruesos y basófilos. Son los gránulos de queratohialina, que no están rodeados por una membrana y que van a contribuir a formar material citoplasmático interfilamentoso del estrato córneo (Junqueira \& Carneiro, 2000).

Las células de éste estrato también contienen gránulos de recubrimiento de membrana. El contenido de estos se libera mediante exocitosis al espacio extracelular y forma láminas de sustancia rica en lípidos que actúan como una barrera impermeable, una de las funciones de la piel (Gartner \& Hiatt, 2002).

La capa delgada clara, homogénea, de tinción ligera de células justo superficial al estrato granuloso es el estrato lúcido (Gartner \& Hiatt, 2002). El estrato lúcido es una capa de células muertas, compacta 
delgada, totalmente queratinizada (Muller et al., 1993). Esta rara vez se presenta en la piel con pelo, las regiones que no lo poseen y es prominente en las zonas de la piel de mucho espesor. Se produce una compactación de varios estratos de células totalmente queratinizadas y translúcidas para así formar una zona clara delgada (Colahan et al., 1998). También se pueden ver desmosomas entre las células (Junqueira \& Carneiro, 2000).

El estrato de células cornificadas es el más numeroso en células y éstas son las de mayor tamaño que cualquier otro estrato de la epidermis (Reed et al., 2005). Las zonas carentes de pelo poseen una mayor cantidad de estas células que las regiones con pelos (Colahan et al., 1998). Las células son grandes, aplanadas y poliédricas; se superponen en los bordes y se asocian a través de crestas interbloqueantes y desmosomas modificados (Reed et al., 2005). Estas células carecen de núcleos y organelos pero están llenas de filamentos de queratina incluidos en una matriz amorfa. Las células más alejadas de la superficie de la piel muestran desmosomas, en tanto que las que se encuentran cerca de la superficie de la piel, llamadas células escamosas o córneas, pierden sus desmosomas y descaman (esfacelan) (Gartner \& Hiatt, 2002).

- Membrana basal: La zona de la membrana basal es la interfase fisicoquímica entre la epidermis y la dermis. Esta zona es importante en: 1) el anclaje de la epidermis a la dermis, 2) el mantenimiento de una epidermis funcional y proliferativa, 3) el mantenimiento de la arquitectura tisular, 4) la cicatrización de heridas, y 5) el funcionamiento como una barrera (Muller et al., 1993); se puede observar con la tinción del ácido periódico de Schiff (PAS). La microscopía electrónica diferencia cuatro estratos: la membrana plasmática de las células basales y sus hemidesmosomas y tonofilamentos; la lámina lúcida; la lámina basal y los componentes fibrosos subyacentes que se extienden hacia la dermis (Colahan et al., 1998).

2.3. Dermis: La dermis conecta la epidermis al tejido subcutáneo (Colahan et al., 1998); es responsable por la mayor parte de la resistencia a la tracción y la elasticidad de la piel, participa en la remodelación, mantenimiento y reparación de la piel y también modula la estructura y función de la epidermis (Muller et al., 1993). En los animales, es costumbre dividir la dermis en dos capas: superficial y profunda. La superficial se caracteriza por fibras colágenas más laxas y delgadas, mientras que la profunda consta de fibras colágenas con una disposición más compacta (Colahan et al., 1998).

La dermis contiene varias células que son esenciales para el normal funcionamiento de la piel. La dermis contiene elementos celulares tales como fibroblastos, macrófagos, histiocitos, eosinófilos y mastocitos, en las matrices fibrosa y no fibrosa. La primera consiste en fibras colágenas y elásticas. La segunda está formada por glucosaminoglicanos y proteoglicanos (Reed et al., 2005). También contiene los apéndices epidérmicos, los músculos erector pili, los vasos sanguíneos y linfáticos, los nervios (Muller et al., 1993), las glándulas sebáceas y apocrínas. Las glándulas sebáceas y apocrínas en el caballo son más grandes y más numerosas, en comparación con las otras especies de grandes animales (Reed et al., 2005).

- Anexos: Los anexos o apéndices epidérmicos son estructuras epiteliales especializadas derivadas del ectodermo, que se encuentran en la dermis pero que permanecen conectadas a la epidermis. Incluyen los folículos pilosos, glándulas sudoríparas apocrínas y glándulas sebáceas (Colahan et al., 1998).

\section{Estructuras adicionales relacionadas con la piel}

Los caballos y otros équidos tienen estructuras cutáneas únicas de estas especies, incluyendo el espejuelo, el espolón y el casco. El espolón es una pequeña masa de tejido cornificado localizado en el cúmulo de pelos que hay en la superficie flexora del menudillo. Es un vestigio de los dedos segundo y cuarto de los équidos extintos. El espejuelo es una masa de tejido córneo localizada en la superficie medial del radio, y se cree que es un vestigio del primer dedo. El casco es la cobertura córnea localizada sobre la extremidad distal del tercer dedo. El casco incluye la ranilla, importante para la absorción de las fuerzas de choque y la estimulación del flujo sanguíneo del pie, y otros componentes que proporcionan una estructura firme para facilitar el movimiento (Reed et al., 2005).

\section{Funciones}

La piel es el órgano más grande y uno de los más importantes del cuerpo. Sin la piel, las personas o los animales morirían. Según Muller et al. (1993), las funciones de esta son: 
Barrera circundante: la función más importante de la piel es hacer posible un medio interno para los demás órganos mediante el mantenimiento de una barrera efectiva para la pérdida de agua, electrolitos y macromoléculas.

Protección ambiental: una función corolaria es la exclusión de los agentes nocivos externos (químicos, físicos y microbiológicos) del ingreso hacia el medio interno.

Movimiento y forma: la flexibilidad, la elasticidad y la resistencia de la piel posibilitan el movimiento y proporcionan figura y forma.

Producción de anexos: la piel produce estructuras queratinizadas.

Regulación de la temperatura: la piel juega un rol en la regulación de la temperatura corporal mediante su sostén del manto piloso, regulación del suministro sanguíneo cutáneo y función de las glándulas sudoríparas.

Almacenamiento: la piel es un reservorio de electrolitos, agua, vitaminas, grasas, carbohidratos, proteínas y otros materiales.

Indicador: la piel puede ser un indicador importante de salud general, enfermedad interna y los efectos de sustancias aplicadas tópicamente o tomadas internamente.

nmunorregulación: los queratinocitos, las células de Langerhans y los linfocitos, en conjunto, proporcionan a la piel una capacidad de inmunovigilancia que previene en forma eficaz la aparición de neoplasias e infecciones cutáneas persistentes.

Pigmentación: los procesos tegumentarios (formación de melanina, vascularidad y queratinización) ayudan a determinar el color del manto y piel. La pigmentación de la piel colabora en la prevención de lesiones por la radiación solar.

Acción antimicrobiana: la superficie de la piel tiene propiedades antibacterianas y antimicóticas.

Percepción sensitiva: la piel es un órgano de los sentidos primarios para el tacto, presión, dolor, prurito, calor y frío.

Secreción: la piel es un órgano secretor en virtud de sus glándulas.

Excreción: la piel actúa en forma limitada como órgano excretor.

Control de la presión sanguínea: los cambios en el lecho vascular periférico afectan la presión sanguínea.

Producción de vitamina D: la vitamina D es producida en la piel mediante la estimulación con la radiación solar.

\section{Evaluación clínica general}

- Historia (anamnesis): el clínico debe obtener una anamnesis completa en todos los casos. Algunos dermatólogos prefieren un examen cutáneo rápido al principio, de modo que se puedan destacar las preguntas más relevantes en el interrogatorio, en tanto que se excluyen las superfluas (Muller et al., 1993). La historia del caballo puede proporcionar al veterinario una guía útil para ayudar a determinar la causa subyacente de un problema dermatológico (Reed et al., 2005).

Según Colahan et al. (1998), para el diagnóstico de una enfermedad cutánea es importante contar con todos los datos y antecedentes del animal. La información debe incluir:

Datos referidos a raza, color, edad, sexo, estado reproductivo, desparasitaciones y vacunaciones.

Descripción de las lesiones: aspecto, progreso (evolución), localización, momento de aparición y grado de prurito (si lo hay).

- Examen físico general: al comenzar el examen físico es importante hacer una exploración clínica completa para determinar la actitud y el aspecto general del animal. Un examen físico general se debe llevar a cabo para determinar si la enfermedad ésta limitada a la piel o si fueran signos sistémicos de enfermedad (Smith, 2002).

Las anomalías cutáneas suelen apreciarse a distancia, incluyen cambios en el pelo, sudación anormal, presencia de lesiones difusas o discretas, muestras de suciedad por supuraciones o de comezón. En los animales débiles, el pelo de invierno puede permanecer pasado el tiempo normal (Radostis et al., 2002).

La descripción visual correcta de las lesiones y la determinación de su distribución son de gran utilidad, al igual que la realización de buenos registros, tanto para la discusión del caso como en la búsqueda del diagnóstico. Las lesiones primarias son más indicativas de la patogénesis que las secundarias que suelen ser el resultado de la automutilación, infección secundaria y tratamientos previos (Colahan et al., 1998). 
- Clasificación de las lesiones dermatológicas:

Lesiones primarias: las lesiones primarias están directamente asociadas con el proceso de la enfermedad. No son patognomónicas pero proporcionan una clave muy valiosa sobre el tipo de proceso morboso que se está desarrollando (Harvey \& McKeever, 2001), se desarrollan espontáneamente sobre la piel sana, como resultado de la acción de la patología subyacente (Ruiz, 2005).

Mácula: Lesión circunscrita, plana (no apreciable por palpación), mayor de $1 \mathrm{~cm}$, caracterizada por un cambio de color de la piel. Se denomina mancha cuando es mayor de $2 \mathrm{cms}$ (Rejas, 2003).

Pápula: Pequeña lesión circunscrita, sólida a la palpación, plana o con elevación, reflejo de una condensación de la epidermis o de la dermis superficial. Se denomina placa cuando es de mayor tamaño, con cabeza plana, formada por la confluencia de pápulas (Rejas, 2003).

Habón o roncha: Lesión claramente circunscrita, plana o elevada, pruriginosa, blancorosácea que blanquea mediante la diascopia, de forma redonda-alargada, resultado de un edema que aparece y desaparece en minutos-horas, siendo característica la elevación de los pelos que lo recubren (Rejas, 2003).

Nódulo: Infiltrado de células inflamatorias o neoplásicas, más o menos circunscrita, que se extiende en capas más profundas de la piel. Normalmente no afecta a la superficie cutánea siendo explorado mediante palpación, percibiéndose una masa firme inserta dentro de la piel. Ante un nódulo de tamaño superior, de tejido neoplásico, se habla de tumor (Rejas, 2003).

Vesícula: Elevación de la epidermis claramente circunscrita, llena de un fluido claro. En perros y gatos se transforma rápidamente en pústula. Cuando es mayor de $1 \mathrm{~cm}$ se denomina ampolla o flictena (Rejas, 2003).

Pústula: Elevación pequeña y circunscrita de la epidermis, llena de pus (Rejas, 2003).

Lesiones secundarias: Las lesiones secundarias provienen de las primarias o son producidas por el propio animal o por factores externos, como traumatismos o medicaciones. Rejas (2003) las clasifica de la siguiente forma:

Alopecia: Falta completa de pelo en los lugares donde existe normalmente.

Escama: Lámina blanca, amarilla o grisácea que se desprende espontáneamente de la capa córnea de la piel.

Collarete epidérmico: Escama con forma circular, formada a partir de vesícula, bulla o pústula rota.

Escara: Tejido necrosado y negruzco, de distintos tamaños, que permanece adherido un tiempo.

Costra: Masa sólida originada por la desecación de exudado, sangre, pus o medicamentos, que permanece adherida a la superficie cutánea.

Erosión: Pérdida superficial de sustancia que no se extiende más allá de la epidermis, respetando la membrana basal, curando sin cicatriz.

Úlcera: Pérdida de sustancia más profunda que la erosión, afectando a la dermis, dejando en su curación una cicatriz.

Fisura o grieta: Hendidura lineal en la epidermis o hasta la dermis. Aparece en las uniones muco-cutáneas, como las comisuras labiales y pliegues perianales, y en los pliegues naturales de la piel.

Tejido conjuntivo o fibroso de reparación que ha reemplazado la dermis o hipodermis, dañadas por un traumatismo, una quemadura o una lesión inflamatoria dérmica intensa.

Hiperqueratosis: Engrosamiento de la capa córnea de la epidermis.

Liquenificación: Engrosamiento y endurecimiento de la piel, caracterizada por una acentuación de las líneas cutáneas, similar a una calle con adoquines.

Esclerosis: Induración de la piel y tejido subcutáneo.

Absceso: Colección purulenta delimitada, blanda, caliente, dolorosa y fluctuosa a la palpación, localizada en dermis o tejido subcutáneo.

Quiste: Cavidad limitada por una pared conjuntiva tapizada por epitelio con contenido fluido o sólido; a la palpación puede ser blando, fluctuoso o como una masa sólida. 
Según Colahan et al. (1998), siempre se debe observar la configuración de la lesión, ya que la presencia de ciertos patrones puede indicar ciertos tipos de procesos patológicos. Las posibles configuraciones incluyen:

Lineal: recuerda a una línea.

Anular: como un anillo.

Policíclica: tiene más de un anillo.

Serpingosa: línea curva u ondulada que recuerda la fisonomía de una víbora.

Blanco: la lesión se encuentra rodeada por uno o más anillos concéntricos

Examen especial de piel.

Al iniciar el examen de la piel, el caballo se mira a cierta distancia, a los efectos de tener una idea general de la distribución y extensión de la enfermedad (Colahan et al., 1998). Nada más que una inspección sistemática y cautelosa es lo requerido para establecer el diagnóstico de muchas dermatosis (Muller et al., 1993).

Las lesiones deben observarse con atención para describirlas en la forma correcta. Por lo tanto, es esencial contar con buena luz; puede ser necesario tener que recortar el pelo alrededor de la lesión, en especial en animales con manto piloso denso (Colahan et al., 1998).

La luz diurna normal sin resplandor es lo mejor, pero cualquier luz artificial de potencia lumínica adecuada es suficiente si produce una iluminación uniforme y clara. Una combinación de lupa y luz proporciona magnificación del campo y también iluminación (Muller et al., 1993).

Después de obtener una impresión a distancia, la piel se debe explorar más cercanamente (Muller et al., 1993), las membranas mucosas deben ser examinadas y la superficie de la piel palpada para determinar rasgos no notados visualmente (Smith, 2002).

Hay que registrar las características de la piel considerando el espesor, la sensibilidad, el prurito, la plegabilidad y si presenta olor. Además, se informa la presencia de cualquier tipo de mosca o parásito externo (Colahan et al., 1998).

La evolución de las lesiones debe ser determinada ya sea mediante la anamnesis o por el descubrimiento de estadios diferentes de lesiones en el mismo paciente. Las pápulas evolucionan a pústulas, que pueden romperse y dejar erosiones o úlceras y finalmente costras (Muller et al., 1993).

El médico veterinario siempre debe realizar un examen físico completo, incluyendo la determinación de la temperatura corporal, las frecuencias cardiaca y respiratoria. Si existe una anormalidad en cualquiera de estos parámetros, el caballo puede tener una enfermedad sistémica o más de un problema médico (Reed et al., 2005).

\section{Métodos complementarios.}

Las pruebas de laboratorio a realizar se seleccionan después de revisar los resultados del examen físico (Colahan et al., 1998), para así descartar otras posibles patologías que puedan estar afectando la piel y ser más certero en el diagnóstico.

Uno de los usos más comunes de la citopatología diagnóstica es la valoración de lesiones cutáneas y subcutáneas y puede ser una herramienta clínica extremadamente útil. Las lesiones cutáneas y subcutáneas son fácilmente accesibles y no hay contraindicaciones significativas en la toma de muestras. Raramente es necesaria la sedación y/o anestesia para su recogida (Cowell et al., 2003).

Las muestras citológicas pueden obtenerse con un hisopo, por raspado y/o realizando una biopsia con aguja fina (BAF) de la lesión (Cowell et al., 2003).

Siempre que sea posible deben prepararse varios frotis, dejando algunos de ellos sin teñir, para eventuales tinciones especiales (Cowell et al., 2003).

Es factible examinar tumores, fístulas, infecciones fúngicas profundas o cualquier otra lesión que presente exudado (Colahan et al., 1998). 
Raspaje cutáneo.

Según Colahan et al. (1998), en dermatología siempre debiera efectuarse un raspaje cutáneo y casi nunca se lo debe omitir.

Los frotis de raspados pueden prepararse a partir de tejidos obtenidos en necropsia o cirugía, o bien en lesiones externas en animales vivos. La principal ventaja del raspado es que con él se obtienen muchas células del tejido, por lo cual es recomendable practicarlo en lesiones que por sus características proporcionan pocas células. Sus principales desventajas consisten en la dificultad de obtención y en que las muestras solo son superficiales. Por ello, con el raspado de lesiones superficiales sólo suelen detectarse infecciones bacterianas secundarias y/o displasia tisular inducida por inflamación, lo cual desaconseja su uso en el diagnóstico de una neoplasia (Cowell et al., 2003).

El raspado de lesiones cutáneas se hace frotando con el borde de un instrumento poco afilado, con un portaobjetos o el dorso de una hoja de bisturí. De este modo acumulamos células a lo largo del borde del borde del instrumento. A continuación, extenderemos estas células en un portaobjetos limpio y seco. Los raspados se realizan sosteniendo una hoja de bisturí perpendicularmente a la superficie limpia y seca de la lesión, y pasando la hoja varias veces en dirección a quien realiza la operación (Cowell et al., 2003) También es beneficioso mantener parte de la mano sobre el animal para que éste, la hoja de bisturí y la mano se muevan como una unidad, evitando la laceración del animal en movimiento (Colahan et al., 1998).

Para la selección del lugar se deben tener en cuenta las lesiones activas recientes o las no alteradas por tratamientos previos ni por excoriaciones. Si no se pueden encontrar este tipo de lesiones, se raspan las presentes. Si son múltiples se toman muestras de más de un sitio registrando su localización (Colahan et al., 1998).

Impronta.

Las improntas pueden prepararse a partir de lesiones externas en animales vivos o a partir de tejidos extirpados en operaciones quirúrgicas o en necropsias (Cowell et al., 2003).

Las improntas de lesiones se hacen eliminando cualquier costra que cubra la lesión y tocando después la superficie de la lesión con un portaobjetos limpio y seco. Después limpiaremos la lesión con un antiséptico no irritante, la secaremos con una gasa u otro material absorbente, y lo reimprontaremos. Si no secamos el tejido antes de realizar las improntas, por lo general, los portaobjetos solo contendrán sangre/fluido tisular (Cowell et al., 2003).

Aunque las improntas son fáciles de realizar y no son dolorosas para el paciente, tienen limitaciones similares a las del frotis. Dependiendo del tipo de lesión, habitualmente no dan células suficientes para la evaluación. Las células específicas como las inflamatorias o las de tumores de células redondas, se desprenden bien con las improntas. Las improntas de lesiones exudativas o ulcerosas son las más útiles para identificar la presencia de agentes infecciosos (Cowell et al., 2003).

Las improntas a partir de úlceras deben realizarse antes de limpiar estas (Cowell et al., 2003).

Si se sospecha de una infección por Dermatophilus congolensis, también haremos una impronta de la parte inferior de la costra. En este tipo de lesiones, las improntas de la parte interna de las costras son más efectivas (Cowell et al., 2003).

Hisopos: un hisopo o cotonete es un instrumento utilizado para recoger muestras, para su posterior estudio. Tiene forma de bastoncillo acabado en una punta de algodón. Excepto para la citología vaginal, los hisopos para recoger muestras se utilizan únicamente cuando no podemos hacer improntas, raspados o aspirados. Al realizar un frotis (con un hisopo estéril humedecido) de la superficie de una úlcera cutánea a menudo solo obtendremos muestra de la superficie inflamada. Para humedecer el hisopo utilizaremos fluido isotónico estéril, como el $\mathrm{NaCl}$ al 0,9\%, aunque las lesiones muy húmedas no lo requieren. Humedecer el hisopo ayuda a minimizar el daño celular durante la toma de la muestra, haremos rodar el hisopo a lo largo de la superficie de un portaobjetos limpio. No se debe frotar el hisopo en la superficie porqué provoca excesivo daño celular. Si utilizamos una tinción de tipo hematológico, el frotis debe dejarse secar al aire y teñirse (Cowell et al., 2003).

Biopsias de masas con aguja fina: la biopsia con aguja fina (BAF) es el método preferido para obtener muestras de masas. La BAF evita la contaminación que puede darse en raspados o improntas, y permite recoger células de diversas áreas dentro de la lesión, lo cual ayuda a obtener material representativo. La BAF puede realizarse usando tanto la técnica de aspiración como la técnica sin aspiración. 
El método usado depende del tipo de 24 lesión y de la preferencia y la experiencia del veterinario. La técnica sin aspiración permite un mejor control de la punta de la aguja y es útil en muchas lesiones, sobretodo en biopsias de lesiones profundas guiadas por ultrasonido. Dicha técnica también se utiliza en lesiones o con órganos altamente vascularizados, al obtener células limitando la contaminación con sangre. La técnica con aspiración puede ser necesaria en pequeñas lesiones en las que la aguja no puede avanzar suficientemente durante la punción para recoger las muestras celulares (Cowell et al., 2003).

La BAF es ciertamente necesaria en superficies no ulcerosas y no erosionadas. En general, la BAF es la más apropiada para obtener adecuadamente una preparación celular representativa de la lesión. Las BAF pueden hacerse junto con improntas o frotis si se desea. La mayoría de lesiones cutáneas y subcutáneas son adecuadas tanto para la técnica de aspiración como para la de no aspiración; a veces es prudente hacerlo utilizando ambas técnicas, especialmente si al intentar el primer método obtenemos poco material o está muy contaminado con sangre. Si es suficientemente grande, deberemos tomar varias muestras de la masa en diferentes áreas para aumentar las posibilidades de obtener material diagnóstico (Cowell et al., 2003).

Los aspirados de masas llenas de fluido y quistes pueden hacerse con una aguja de 22-25 GA unida a una jeringa de $3 \mathrm{cc}$. Cuando sea posible deberemos aspirar suficiente fluido para preparar varias muestras citológicas, realizar un recuento de células nucleadas y un análisis de proteínas totales, y realizar y proponer un cultivo. Normalmente es suficiente con 1-3 cc (Cowell et al., 2003).

Cuando las lesiones contienen tanto áreas sólidas como fluidas, hace falta realizar aspiraciones por separado de ambas, porque las poblaciones de células que podemos encontrar posiblemente sean muy distintas (Cowell et al., 2003).

Biopsia de piel: las biopsias de piel se obtienen para establecer un diagnóstico específico, descartar otros, seguir el curso de la enfermedad o confirmar si la escisión tumoral fue o no completa (Colahan et al., 1998).

Las lesiones que deben ser sometidas a biopsias incluyen las aisladas, las sospechosas de ser neoplásicas, úlceras persistentes, cualquier dermatosis que no responde a tratamiento apropiado y cualquier dermatosis grave o atípica (Colahan et al., 1998).

El fijador universal para las biopsias de piel es la solución de formol al 10\%, manteniendo una relación fijador: tejido de 10: 1 (Colahan et al., 1998).

Los tres tipos principales de biopsias de piel, útiles para el diagnóstico de problemas cutáneos son: por sacabocados, escisión parcial o en cuña (biopsia incisional) y escisión completa (biopsia escisional). La elección dependerá del tipo, tamaño y localización de la lesión y su probable profundidad en la piel y los tejidos subyacentes (Colahan et al., 1998).

\section{Flora normal.}

La flora cutánea está conformada por bacterias, hongos y parásitos, y se divide en 2 grandes grupos: la flora residente y la flora transitoria (Santamaría, 2002).

Los organismos que presentan capacidad de multiplicarse y sobrevivir adheridos a la superficie cutánea son los llamados residentes, los cuales se encuentran como constituyentes dominantes de la piel (Santamaría, 2002).

Los constituyentes de la flora transitoria simplemente son depositados en la superficie de la piel desde el medio ambiente, pero no tienen la capacidad de adherirse a ella (Santamaría, 2002).

Las superficies dérmica y mucosa proporcionan una barrera protectora que preserva la vida, compuesta por defensas físicas, químicas y microbianas. La flora normal contribuye con esta barrera protectora contra los patógenos y, a su vez, aporta paradójicamente, una fuente para posibles invasiones oportunistas. Las bacterias comensales son aquellas que se benefician por vivir sobre o dentro de un huésped sin crear peligro. Para que una relación sea la de comensal debe haber un beneficio mutuo y la interrupción de esta asociación da lugar al desarrollo de una anormalidad o una enfermedad en el huésped. Un patógeno es cualquier microorganismo productor de una enfermedad; de esta manera, un microorganismo comensal tiene la posibilidad de ser patogénico (Reed et al., 2005).

La combinación de la flora normal y la inmunidad de las mucosas proporcionan una barrera eficaz contra la colonización infecciosa de las superficies cutáneas no interrumpidas (Reed et al., 2005). La mayoría de los microorganismos son encontrados en las capas más superficiales de la epidermis y en la parte 
superior del folículo piloso (SØRUM \& Sunde, 2001). La mayoría de las bacterias y hongos localizados sobre la superficie de la piel no están asociados con enfermedad. Sin embargo, las levaduras y las bacterias que se sitúan dentro de los folículos pilosos tienen una mayor probabilidad de estar relacionadas con un proceso patológico. Aun cuando los caballos vivan en un ambiente muy contaminado con flora fecal, la flora dérmica normal de ésta especie estará asombrosamente desprovista de miembros de la familia Enterobacteriaceae. Los habitantes normales incluyen poblaciones mixtas de bacterias de las especies de Acinobacter, Aerococcus, Aeromonas, Bacillus, Corynebacterium, Flavobacterium, Micrococcus, Nocardia, Staphylococcus coagulasa negativa, Staphylococcus aureus, Streptomyces y Streptococcus no hemolíticos. Ciertos Staphylococcus spp se han asociado con enfermedades cutáneas del caballo y éstos incluyen $S$. aureus, $S$. intermedius y $S$. hyicus, mientras que especies tales como $S$. xylosus y $S$. sciuri se asocian con mayor frecuencia con la piel normal (Reed et al., 2005). Zubrod et al. (2004) en un estudio realizado en 24 caballos para determinar la presencia de bacterias en el sitio de realización de artrocentesis determinó la presencia de Actinomyces spp., Corynebacterium spp. y Escherichia coli.

Dermatopatías bacterianas de importancia en medicina equina

Dentro de las dermatopatías relevantes en medicina equina existe una gran variedad en cuanto a su presentación y las características de las lesiones que estas producen, es por ello que se las clasificó de acuerdo a las lesiones que estas causan.

Enfermedades caracterizadas por ronchas, pápulas o nódulos pequeños:

Micobacteriosis: las micobacterias son microorganismos aerobios 0 microaerófilos, quimioorganotrofos, y su temperatura óptima de crecimiento se sitúa entre 30 y 45 ㄷ․ Utilizan glicerol o piruvato como fuente de carbono y energía, y como fuente de nitrógeno pueden utilizar asparagina, glutamato y amonio (Sevilla, 2007).

Los caballos rara vez se ven afectados por ésta patología, si bien se infectan con $M$. avium con una frecuencia relativamente mayor que con M. bovis (Colahan et al., 1998; Carter et al, 2007). Lloyd et al. (2003), indican también a Mycobacterium intracellulare, M. smegmatis como causa de tuberculosis.

La infección suele tener lugar a través del tracto alimentario, con complejos primarios relacionados con la faringe y con el intestino. En la forma cutánea los granulomas ulcerados se pueden encontrar en la parte superior de los miembros y abdomen (Carter et al., 2007). Las lesiones secundarias pueden encontrarse en el pulmón, en el hígado, en el bazo y en las serosas (Biberstein \& Chung Zee, 1994).

La tuberculosis tegumentaria (o cutánea) es rara en los caballos. Está causada por Mycobacterium spp que infecta a los pájaros, bovinos y personas (Colahan et al., 1998). Sevilla (2007) señala que, la infección con Mycobacterium avium sp. paratuberculosis ha sido inducida artificialmente en experimentos con rumiantes salvajes y no rumiantes como animales de laboratorio, cerdos, caballos, gallinas, y otras especies.

Los caballos afectados están emaciados y a menudo tienen un compromiso vertebral. En raras ocasiones se han asociado nódulos subcutáneos que pueden ulcerarse con una infección generalizada (Colahan et al., 1998).

El diagnóstico diferencial incluye otras enfermedades cutáneas nodulares, como linfosarcoma cutáneo, amiloidosis y esporotricosis, así como otras enfermedades que pueden causar pérdida de peso y debilidad. El diagnostico se realiza por la demostración de microorganismos ácido-alcohol resistentes en las improntas citológicas realizadas a partir del contenido de los nódulos o por medio de cortes histológicos. El diagnóstico definitivo se realiza con el cultivo del microorganismo causal. Las características histopatológicas incluyen la presencia de células epitelioides y células gigantes de Langerhans (Colahan et al., 1998). El diagnóstico de tuberculosis en equinos es mayormente realizado en necropsias (Carter et al., 2007). La prueba de tuberculina no es útil en los caballos debido a que hay muchos reactores inespecíficos (Colahan et al., 1998).

El tratamiento no es recomendable o factible de realizar cuando la enfermedad es generalizada; lo más recomendable es la resección quirúrgica de los granulomas (Carter et al., 2007)

Los fármacos principales empleados para el tratamiento de infecciones por Mycobacterium son la isoniacida $(2 \mu \mathrm{g} / \mathrm{ml}$; dosis indicada para pacientes humanos). En medicina equina se utiliza rifampicina (5-10 $\mathrm{mg} / \mathrm{kg}$, p.o., cada $5 \mathrm{hrs}$ ). Otro fármaco de primera línea en caballos es estreptomicina $(10 \mathrm{mg} / \mathrm{kg}, \mathrm{i} . \mathrm{m}$., cada 12 hrs.) (Baggot, 2001; Prescott et al., 2002). 
El tratamiento no se recomienda por los costos, la posibilidad de zoonosis y el pronóstico desfavorable (Colahan et al., 1998).

Enfermedades caracterizadas por masas o nódulos granulomatosos y fistulización

Algunas bacterias pueden causar abscesos y lesiones granulomatosas y fistulizantes. Estas incluyen Staphylococcus, Streptococcus, Corynebacteryum, Actynomices y otros géneros. Algunas de estas infecciones se asocian con distintos síndromes mientras otras son simplemente el resultado de la contaminación de heridas. Los abscesos refractarios por Brucella o infecciones no brucelosas ocurren en ocasiones en las bolsas sinoviales, causando síndromes de fistulización de la cruz o la nuca (Colahan et al., 1998).

La administración de antibióticos puede demorar la ruptura del absceso y prolongar la enfermedad. Se deben aplicar paños calientes para lograr la maduración de los abscesos. Una vez establecido el drenaje las lesiones suelen cicatrizar con antibióticos o sin ellos. Sin embargo, la antibióticoterapia se indica si se presenta fiebre o enfermedad sistémica (Colahan et al., 1998).

Botriomicosis (Granuloma estafilocócico)

Botriomicosis, actualmente llamada pseudomicetoma bacteriano; y también actinofitosis estafilocócica, granuloma bacteriano, bacteriosis granular ó pseudomicosis bacteriana; es una enfermedad crónica piogranulomatosa raramente reportada. Dicha condición fue originalmente reportada en caballos por Bollinger en 1870. La enfermedad fue llamada originalmente - Botriomicosis (del Griego - Botrys que significa racimo de uvas; y -Micosis indicativo de una condición causada por un hongo). Luego fue descubierto que era una enfermedad causada por una bacteria. El término actualmente usado pseudomicetoma bacteriano - enfatiza el origen bacteriano de un desorden que clínica e histopatológicamente aparenta ser un micetoma eumicótico (realmente micótico) (Scott, 2007). Luego de su primer reporte y por las siguientes tres décadas la Botrimicosis fue juzgada como una enfermedad que solo afecta a los animales (Miller et al; 2001).

El pseudomicetoma bacteriano cutáneo ha sido reportado en caballos, ganado vacuno, ovejas, gatos, cerdos, ratones, cebras, hámster enano y humanos (Scott; 2007).

Numerosas bacterias han sido aisladas - y en ocasiones asociaciones de bacterias diferentes han sido aisladas: Pseudomonas aeruginosa, Escherichia coli, Protteus spp., estreptococos $\alpha$-hemolíticos, Propionibacterium agnes, Serratia marsescens, Peptostreptococcus spp., Moraxella nonliquefaciens, Micrococcus sp., Pasteurella multocida, Corynebacterium sp. y Neisseria sp. (Scott, 2007). Hay informes de Actynomices viscosus que causan botriomicosis equina (Kobluk et al., 1995). La bacteria comúnmente aislada es Staphylococcus aureus (Miller et al; 2001).

Los estafilococos son bacterias grampositivas de forma redonda que se dividen en varios planos para formar agrupaciones irregulares. En los exudados forman racimos, parejas o cadenas cortas (Biberstein \& Chung Zee, 1994).

Los estafilococos son bacterias catalasa-positivas, anaerobias facultativas que utilizan los hidratos de carbono tanto por oxidación como por fermentación (Kobluk et al., 1995).

Los estafilococos están ampliamente difundidos en la naturaleza. Su hábitat natural es la piel y las membranas mucosas de los mamíferos y las aves. También pueden encontrarse de forma transitoria en el tracto intestinal. No obstante, la difusión de cepas de estafilococos entre diferentes especies animales es limitada (Vadillo et al., 2002).

El Granuloma bacteriano comienza, presumiblemente, como una lesión traumática de la piel durante la cual un microorganismo infeccioso es inoculado en la dermis. Se desarrolla una reacción granulomatosa porqué el microorganismo es capaz de provocar una respuesta del huésped, pero éste es solo capaz de contener la infección pero no de erradicarla (Reed et al., 2005; Scott, 2007).

Como la infección ocurre por contaminación de una herida, los sitios más afectados son los miembros, el escroto y las áreas que pueden ser rascadas (Colahan et al., 1998). Las lesiones de Botriomicosis cutánea se caracterizan a menudo por pápulas, nódulos o placas, o combinaciones de éstas; firmes, indoloros y no pruríticos. Las lesiones pueden ser de ubicación dérmica o subcutánea. En asociación con las lesiones primarias se desarrollan eventualmente uno o más tractos de drenaje. Estos tractos de drenaje pueden contener gránulos, típicamente pequeños (1 a $2 \mathrm{~mm}$ de diámetro) de color blanco y con apariencia de arena (Scott, 2007) 
El diagnóstico diferencial incluye otras infecciones bacterianas (actinomicosis, nocardiosis, enfermedad micobacteriana) o fúngicas (micetoma eumicótico, pseudomicetoma dermatofitico, esporotricosis o micosis sistémicas), granulomas por cuerpo extraño, piogranuloma estéril, habronemiasis y neoplasias (Kobluk et al., 1995; Scott, 2007). La presencia de gránulos es más sugestiva de botriomicosis, nocardiosis y actinomicosis (Kobluk et al., 1995).

El diagnóstico se basa en la citología, cultivo bacteriano y biopsia de piel (Kobluk et al., 1995; Scott, 2007). La biopsia de piel es un método complementario útil, ya que el examen histopatológico revela un infiltrado nodular o difuso, granulomatoso a piogranulomatoso que rodea a gránulos que contienen bacterias, todo rodeado por material eosinofílico (Colahan et al., 1998). El examen citológico de los exudados conseguidos por impronta o aspiración con aguja fina revelan una inflamación supurativa a piogranulomatosa. Usualmente no se observan bacterias a menos que se examinen los gránulos (Scott, 2007).

La escisión quirúrgica completa - cuando es posible - es el tratamiento de elección. La terapia antibiótica sistémica puede no ser curativa y las recaídas (recidivas) son comunes. Esto puede ocurrir porque los tejidos de granulación son relativamente impermeables a los antibióticos (Scott, 2007)

\section{Absceso por corinebacterias}

Corynebacterium spp. son bastones pleomórficos grampositivos (Reed et al., 2005), presentan un amplio rango de requerimientos de oxígeno y pueden ser aerobias, microaerófilas o anaerobias facultativas. Crecen en agar sangre a 37으 C.; las colonias de C. pseudotuberculosis son pequeñas de color naranja o crema y pueden producir una ligera hemólisis. Son catalasa-positivos, y tienen metabolismo fermentativo, las especies patógenas de los animales domésticos fermentan la glucosa (Scanlan, 1991).

Las especies del género Corynebacterium son comunes en el suelo, el agua y en el estiércol contaminado con exudados purulentos, y residen en la piel y las mucosas de hombres y animales, por lo que resulta difícil determinar si son simples contaminantes o tienen poder patógeno. Hasta hace muy poco, la mayoría de las corinebacterias se consideraban micropoblación contaminante con escasa o nula capacidad para causar infecciones. Sin embargo, gracias a la publicación de numerosas revisiones relacionadas con el aspecto clínico de las bacterias coreniformes, al aislamiento continuo de corinebacterias en la sangre, líquido cefalorraquídeo y otros líquidos corporales normalmente estériles, al establecimiento de mejores sistemas de identificación y a un mayor conocimiento de la taxonomía de las corinebacterias, la mayoría de las especies del género Corynebacterium se considera en la actualidad patógenos oportunistas que invaden hospedadores inmunodeprimidos (Gädicke et al., 2008; Vadillo, 2002).

En el año 1959, en caballos del estado de California (EE.UU.) se describió un cuadro durante los meses de calor, el cual se presentó como absceso pectoral y abdominal crónico (APC) desde el cual se aisló e identificó como agente causal Corynebacterium pseudotuberculosis (Gädicke et al., 2008)

El Corynebacterium pseudotuberculosis, además de causar linfangitis ulcerativa, acné contagioso y aborto, induce la formación de abscesos de pared gruesa, de gran tamaño $(10 \times 10 \times 20 \mathrm{~cm}$.), profundos y de evolución lenta. Los abscesos se producen con mayor frecuencia en la región pectoral pero, en ocasiones, también se observan en la axila, ingle o pared ventral del abdomen, 34 desde el ombligo hasta la glándula mamaria o zona prepucial, así como en los miembros, la cara y el cuello. Cuando la enfermedad afecta a la región pectoral o a las regiones inguinales, a veces se llama - fiebre de la paloma y —enfermedad de la tierra seca , respectivamente, en USA (Colahan et al., 1998; White, 2005; Gädicke et al., 2008).

Este tipo de infección profunda por $C$. pseudotuberculosis puede ser contraída en áreas donde es común la linfadenitis caseosa en ovejas, aunque la proximidad a las ovejas no sea un requisito (White, 2005). Se observó una asociación entre la incidencia de la habronemiasis cutánea y el momento de la formación del absceso, conduciendo a la sospecha de que la migración de la larva de Habronema puede llevar la bacteria hacia los tejidos profundos (Colahan et al., 1998). Las lesiones suelen ser estacionales, produciéndose más a menudo durante el verano y el otoño, coincidiendo con el pico de estación de las moscas, en especial con condiciones polvorientas y secas (Reed et al., 2005). Las garrapatas y las moscas, en especial la de los cuernos (Colahan et al., 1998; Reed et al., 2005), transportan el C. pseudotuberculosis vivo y, por lo tanto, pueden ser capaces de inocularlo en los tejidos. La diseminación linfática y la abscedación pueden seguir a este proceso (Colahan et al., 1998). Por razones desconocidas, las picaduras por moscas son susceptibles a infecciones (Reed et al., 2005). En un reporte reciente en el que se realizó un ensayo molecular sensible para 
la detección del gen para la exotoxina de la fosfolipasa D de C. pseudotuberculosis, potenciales insectos vectores fueron identificados, incluidos Hematobia irritans (mosca de los cuernos), Stomoxys calcitrans (mosca de los establos) y Musca domestica (mosca doméstica). C. Pseudotuberculosis fue identificado sobre el $20 \%$ de las moscas domésticas en la vecindad de los caballos enfermos (White, 2005). Varios fomítes pueden verse envueltos en la diseminación (Carter et al., 2007).

Las lesiones se desarrollan con lentitud, y pueden ser únicas o múltiples. Estos abscesos drenan un material cremoso o caseoso que puede tener un color de blancuzco a verdoso. La mayoría de los caballos no demuestra manifestaciones sistémicas de la enfermedad; sin embargo, se puede presentar un edema con 35 signo de hundimiento positivo, dermatitis en la línea media ventral, depresión, fiebre, claudicación, anorexia, pérdida de peso, letargia y dolor abdominal (Reed et al., 2005; Carter et al, 2007; Gädicke et al., 2008). La púrpura hemorrágica puede ser una secuela en los casos prolongados. No hay predisposición por edad o sexo sin embargo la infección raramente se encuentra en animales menores de un año. Se pueden afectar varios caballos de un mismo campo (Colahan et al., 1998; Gädicke et al., 2008).

Alrededor de un $8 \%$ de los caballos con abscesos externos los desarrollan internamente por diseminación hematógena, los cuales pueden afectar el peritoneo, mesenterio, hígado, bazo, riñones, útero, diafragma, pulmones y pleura, con la consecuente pérdida de peso, cólico o la ataxia que éstos pueden causar. Aunque los abscesos internos son menos comunes que los externos, se describen casos de pericarditis y pleuritis causadas por Corynebacterium pseudotuberculosis. La tasa de mortalidad por este agente es muy baja, generalmente se asocia a abscesos internos, animales debilitados o a tratamientos tardíos (Carter et al., 2007; Gädicke et al., 2008).

La frecuencia de aparición de casos de abscesos aumenta generalmente en los meses de calor de años de alta pluviosidad. Como puerta de entrada del agente se sospecha las excoriaciones y grietas en el tegumento. En estudios retrospectivos, se ha determinado que la incidencia aumenta luego de inviernos muy lluviosos, los que mejorarían las condiciones para el desarrollo de insectos en el verano y otoño siguientes. La incidencia de la presentación de los abscesos también varía considerablemente entre los años; una vez que se presenta la enfermedad en una determinada región, podrían continuar apareciendo casos esporádicamente durante los años siguientes (Gädicke et al., 2008).

El diagnóstico se basa en el frotis, cultivo bacteriano, en la estación y en el aspecto del absceso y el exudado (Kobluk et al., 1995, Reed et al., 2005). A la citología, C. pseudotuberculosis aparece como pequeñas barras grampositivas que se agrupan configurando - figuras chinas . Los organismos pueden ser poco numerosos (Kobluk et al., 1995). Debido a que la identificación del organismo en el examen citológico del exudado puede ser difícil, siempre se recomienda realizar un cultivo (Reed et al., 2005). Se puede sospechar de abscesos internos cuando están presentes externamente (Carter et al, 2007).

Muchos informes sugieren que el tratamiento antibiótico temprano pueda estar contraindicado, pues obstaculiza el desarrollo del absceso, y las lesiones pueden empeorar cuando se descontinúa la medicación (Kobluk et al., 1995).

Si no se puede realizar el drenaje, el suministro de grandes dosis de penicilina procaínica $(50,000$ $\mathrm{UI} / \mathrm{kg}$, intramuscular, cada 12 horas) durante un periodo de hasta 6 meses puede ser un procedimiento curativo. Los toxoides y las bacterinas no han sido útiles (Reed et al., 2005).

El tratamiento depende de la zona del cuerpo afectado. Penicilina procaínica (30000 a 50000 $\mathrm{UI} / \mathrm{Kg} /$ diario) con rifampicina (3 a $5 \mathrm{mg} / \mathrm{kg}$ cada $12 \mathrm{hrs}$. PO) o sulfa-trimetoprim (30 Mg/Kg cada 12 hrs. PO) puede ser usado. El tratamiento con sulfa-trimetoprim y rifampicina puede llevar concurrentemente a una mayor incidencia de colitis, y debiera ser evitado. Si se toma la decisión de utilizar los antibióticos, pero el drenaje no se puede establecer fácilmente, los antibióticos se deben utilizar por un mínimo de 1 mes (White, 2005). Si el absceso es solitario y no causa dolor o fiebre, los antibióticos no son generalmente necesarios; pero es importante provocar el drenaje del absceso quirúrgicamente, mediante aplicación de calor o con agentes inductores de calor (ichthymol). Una vez que cualquier absceso ha drenado, la limpieza con yodo o chlorhexidina está indicado (White, 2005; Carter et al., 2007).

Cuando se presentan casos en un predio se recomienda el aislamiento de los animales afectados, control de moscas, mantener un buen estado sanitario de los animales, desinfección de fomites contaminados y una cuidadosa disposición de las camas en las pesebreras; además, la remoción frecuente de la descarga de los abscesos y protección de heridas en casos de dermatitis ventral de la línea media (Gädicke et al., 2008). 37 
Los caballos afectados no parecen desarrollar inmunidad. La enfermedad es potencialmente zoonótica; por lo tanto se debe tener precaución al manejar y tratar caballos afectados (Kobluk et al., 1995).

Linfangitis ulcerativa

Linfangitis ulcerativa es una enfermedad contagiosa de caballos y mulas (Carter et al., 207). Esta es una infección de los vasos linfáticos cutáneos (Reed et al., 2005). Es otro síndrome en donde las bacterias son una de varias posibles etiologías. Cuando la condición es causada por bacterias, es llamada linfangitis ulcerativa (Kobluk et al., 1995).

Usualmente, solo una pierna está envuelta. Las lesiones y la inflamación progresan lentamente, la condición puede tornarse crónica con recaídas (Manual Merck, 2008). La enfermedad ocurre comúnmente en países tropicales y subtropicales (Carter et al., 2007).

El Corynebacterium pseudotuberculosis es la causa más común de linfangitis ulcerativa, aunque en ocasiones se aíslan bacterias piogénicas como Streptococcus spp, Staphylococcus spp, Pseudomonas aaeruginosa, Rhodococcus equi, otras Corynebacterium spp, Pasteurella, Fusobacterium, Actinobacillus y Nocardia (Colahan et al., 1998; Kobluk et al., 1995). Es probable que la inoculación de los microorganismos hacia los tejidos se produzca a través de heridas incluyendo inyecciones, vectores artrópodos, semejantes a larvas de Habronema spp. y moscas de los establos; y contacto con fomítes (Manual Merck, 2008; Carter et al., 2007; Kobluk et al., 1995). Condiciones poco higiénicas y húmedas predisponen a los animales a infecciones particularmente la zona inferior de los miembros. Como sea, la enfermedad también puede ocurrir bajo excelentes condiciones de manejo (Manual Merck, 2008). Carter et al. (2007), mencionan que el agente causal puede vivir en fomites y en el ambiente durante meses.

El comienzo de la linfangitis ulcerativa en caballos es lento usualmente se manifiesta con dolor, el edema de los miembros afectados y la fiebre suelen ser los primeros signos clínicos, seguidos por inflamación, el edema puede extenderse hacia el miembro completo. Las lesiones comienzan como pápulas o nódulos que se rompen y como resultado se producen costras, úlceras, y zonas de drenaje, el exudado es inodoro, espeso, blanco-verdoso y teñido de sangre. Los nódulos que drenan cicatrizan lentamente y se desarrolla uno nuevo en 1 a 2 semanas. Los vasos linfáticos regionales se transforman en cordones y pueden ulcerarse, pero rara vez hay una diseminación hacia los linfonódulos regionales (Manual Merck, 2008; Carter et al., 2007; Kobluk et al., 1995; Colahan et al., 1998). Los miembros afectados pueden estar edematizados porque el drenaje linfático del miembro puede estar comprometido; además se puede presentar dolor, y los caballos a veces están deprimidos (Reed et al., 2005; Colahan et al., 1998). Es posible observar masas tipo coliflor en la región distal de los miembros. En los casos crónicos y graves, los caballos se presentan emaciados y finalmente mueren (Colahan et al., 1998), y es común el hallazgo de un engrosamiento permanente de los tejidos adyacentes a los vasos linfáticos regionales. No hay predisposición por raza, sexo o edad (Reed et al., 2005).

La historia, el examen físico y el cultivo bacteriano - con el respectivo antibiograma - son procedimientos necesarios para llegar al diagnóstico (Colahan et al., 1998). Según Reed et al. (2005) también se debe hacer un frotis directo del exudado y teñirlo con Giemsa o Gram y ver el aspecto de la lesión. El aislamiento de $C$. pseudotuberculosis desde las lesiones es necesario para la confirmación (Manual Merck, 2008). Cultivo fúngico, biopsias de piel, y radiografía de contraste pueden ser necesarias para excluir otras posibles causas (Kobluk et al., 1995).

La biopsia revela una dermatitis superficial y profunda perivascular supurativa a piogranulomatosa que puede transformarse en difusa. Pueden presentarse edema y fibrosis y los microorganismos pueden observarse con tinciones especiales (Colahan et al., 1998).

El diagnóstico diferencial incluye esporotricosis, muermo, histoplasmosis (linfangitis epizoótica), micobacteriosis, actinomicosis, nocardiosis, pioderma, abscesos, linfangitis por otras bacterias (Staphylococcus aureus, Rhodococcus equi, Streptococcus spp. o Dermatophilus spp.), dermatofitosis, criptocococis equina, blastomicosis norteamericana y onchocercasis (Manual Merck, 2008; Colahan et al., 1998).

Es necesario iniciar el tratamiento con rapidez, para evitar la debilidad y la desfiguración permanentes. En los casos iniciales, la hidroterapia, el ejercicio, el drenaje quirúrgico y las grandes dosis de penicilina procaínica (de 20,000 a 80,000 Ul/kg, intramuscular, cada 12 horas) durante un mínimo de 30 días después de llegar a la normalidad, puede ser un esquema curativo, además hay que limpiar el área afectada 
a diario con una copiosa cantidad de agua y un jabón antimicrobiano (clorhexidina). La administración de antiinflamatorios no esteroides puede ser beneficioso (Reed et al., 2005). Carter et al. (2007), recomiendan el uso de penicilina G por vía I.V. sola o en combinación con rifampicina oral hasta la resolución de las lesiones, entonces se administra sulfa-trimetropim o rifampicina oral para prevenir recaídas, además si es necesario remoción quirúrgica de algunos nódulos, aplicación de hot-packs, hidroterapia; irrigación de las heridas y aplicación de ungüentos.

Los casos avanzados pueden no responder bien al tratamiento (Colahan, 1998). Si el área se vuelve fibrótica y se restringe el movimiento articular, el pronóstico es malo (Reed et al., 2005). La prevención exige una buena higiene y desinfección cuidadosa de las heridas (Colahan et al., 1998).

La prevención consiste en aislar los animales infectados. Evitar el amontonamiento de animales y circunstancias que contribuyan a producir injurias (Carter et al., 2007).

Bursitis bacteriana

La Brucelosis es una enfermedad de importancia histórica significante que aun existe en cierta población de animales. Las especies del género Brucella spp. causan enfermedades en cabras, ganado, cerdos, ovejas, perros, delfines, mamíferos marinos, humanos y caballos (Weese, 2002; Gyles et al., 2004; Velasco y Yamasaki, 2002).

Los caballos son relativamente resistentes a la infección, pero la enfermedad puede ocurrir y la brucelosis puede ser transmitida desde los caballos a los humanos. La brucelosis es causada por un cocobacilo gram-negativo Brucella abortus (Weese, 2002).

Brucella spp. son patógenos intracelulares facultativos capaces de sobrevivir y multiplicarse dentro de células fagocíticas y tejido reticuloendotelial; miden 0,5-0,7 $\mu \mathrm{m}$, no tienen agrupación específica, son aerobios estrictos o microaerófilos, no móviles y no forman esporas. Las seis especies reconocidas $-B$. abortus, $B$. melitensis, $B$. suis, $B$. canis, $B$. ovis y $B$. neotomae - son nombradas en base a la preferencia por sus hospederos, cepas adicionales de Brucella spp. no designadas han sido aisladas de mamíferos marinos (Gyles et al., 2004; Velasco \& Yamasaki, 2002). Habitan el tracto genital, glándula mamaria y sistema retículo endotelial de animales afectados. Crecen en agar triptosa o Agar Brucella. Algunos biotipos requieren la adición de suero y 5-10\% de CO2, el crecimiento es lento 2-5 días (Velasco \& Yamasaki, 2002).

La enfermedad en los equinos se manifiesta comúnmente como fístula de la cruz, fístula de la nuca o bursitis fistulosa. El ganado bovino es el mayor reservorio de la infección. El aislamiento de otro organismo bacteriano desde el tracto de drenaje no excluye el compromiso de B. abortus, esto solo refleja colonización secundaria (Weese, 2002).

La Fístula de la Cruz es una condición inflamatoria de la bolsa supraespinosa en el caballo. La bolsa es variable en localización y tamaño, pero generalmente cubre la segunda a quinta vértebras torácicas y puede extenderse ventrolateralmente al margen del cartílago escapular. La mayoría de los casos clínicos se consideran principalmente de origen infeccioso, pero muchos de los casos no se ven hasta que la bolsa fistuliza y la contaminación secundaria se extiende (Smith, 2002). Los microorganismos incriminados en el proceso infeccioso primario son B. abortus y A. bovis (Colahan et al., 1998; Smith, 2002). La contaminación secundaria se produce por microorganismos ambientales tales como Estreptococcus spp., Escherichia coli, también bacterias anaerobias han sido aisladas. El trauma primario a la 41 bolsa o a la vértebra torácica subyacente puede también causar la inflamación bursal. La migración y el enquistamiento de las larvas de Onchocerca cervicalis a través del ligamento nucal y bolsa se han incriminado como causa de fístula de la cruz. (Smith, 2002).

Colahan et al. (1998) indica que en un estudio realizado se observó que, de 14 casos de fístulas en la cruz, el 82\% (11 casos) presentó Streptococcus zooepidemicus. Brucella abortus se aisló en 2 instancias. Cinco caballos fueron sacrificados. La escisión radical, junto con la administración sistémica de antibióticos, fue el tratamiento de elección, pero hubo 30\% de recidivas. Una nueva cirugía resolvió los casos recurrentes

La fístula de la cruz puede desarrollarse abrupta e insidiosamente dependiendo del agente etiológico. Inicialmente, la mayoría de los signos clínicos comunes son dolor, el calor y la hinchazón de la bolsa supraespinosa superpuestos a través de la segunda a quinta vértebra torácica. Letargo, fiebre y rigidez generalizada también pueden estar presentes. Después de varios días a semanas, la bolsa se rompe, lo que resulta en el drenaje de fluido, que puede ser de consistencia serosa o purulenta, a través de una fístula cutánea. Si no reciben tratamiento, la curación aparente, fibrosis, y refistulización pueden ocurrir. La lista de 
diagnósticos diferenciales debe incluir infecciones atípicas causantes de abscesos, tumores, traumas externos que no envuelven la bursa. El contacto con ganado infectado con Brucella es sugestiva de bursitis bacteriana causada por B. abortus (Smith, 2002).

La aspiración percutánea y cultivo microbiológico de fluido desde la bursa antes de su ruptura es útil diagnósticamente. Luego de la ruptura de la bursa, contaminantes bacterianos secundarios pueden interferir con el desarrollo de cultivos puros del microorganismo primario y como resultado observar una descarga purulenta (Smith, 2002). Debido a que B. abortus es difícil de aislar el diagnóstico se basa en la seropositividad (Weese, 2002). Todos los caballos afectados deben ser sometidos a pruebas serológicas en busca de brucelosis y deben remitirse muestras profundas para cultivo si se requiere intentar un tratamiento (Colahan et al., 1998).

El tratamiento de la brucelosis usualmente se restringe a los animales de compañía afectados caninos y equinos - porque la condición en el ganado suele estar controlada por diversos programas de erradicación nacionales. Las estrategias terapéuticas son costosas y suelen incluir la administración crónica de antibióticos que pueden no estar aprobados en animales de abasto. Si bien son susceptibles in vitro, las recidivas son comunes con la monoterapia a base de tetraciclinas, rifampinas y trimetoprim-sulfonamidas. La terapia de elección incluye el uso de oxitetraciclina $(5 \mathrm{mg} / \mathrm{kg}$, cada $12 \mathrm{hrs}$.; E.V.) y estreptomicina (10 $\mathrm{mg} / \mathrm{kg}$; cada12 hrs.; vía I.M.) o gentamicina (6.6 mg/kg; cada 24 hrs.; vía I.M. o E.V.); el gasto del prolongado tratamiento necesario a veces supera el valor de animal, y los aspectos de salud pública deben ser considerados cuidadosamente (Prescott et al., 2002; Manual Merck, 2008). El tratamiento más exitoso es la disección y extracción completa de la bursa infectada (Manual Merck, 2008).

\section{Muermo}

Muermo es una enfermedad bacteriana contagiosa, aguda o crónica, usualmente fatal que afecta caballos, burros y mulas; y es causada por Burkholderia (antiguamente Pseudomonas) mallei y caracterizada por el desarrollo serial de nódulos que se encuentran comúnmente en el tracto respiratorio superior, pulmones y piel. También conocida como linfangitis enzoótica, la enfermedad tiene gran importancia histórica porque fue el azote de grupos de caballería y fue usada durante la Primera Guerra Mundial para infectar los caballos de las tropas enemigas (Kobluk et al., 1995; Colahan et al., 1998; Brown, 2002; Manual Merck, 2008).

Humanos, caninos, felinos y otras especies son susceptibles y la infección usualmente es fatal (Manual Merck, 2008; Al-Ani \& Roberson, 2007). La alta mortalidad suele deberse a bronconeumonía (Colahan et al., 1998). En años recientes la enfermedad fue reportada en Irak, Turquía, Vietnam, Corea, Italia, Rusia, Pakistán, India, Mongolia, China, Brasil y Emiratos Árabes Unidos (Manual Merck, 2008; Al-Ani \& Roberson, 2007).

B. mallei es una bacteria aeróbica gram-negativa, no motil, no esporoformante, tienen forma de varillas delgadas con los extremos redondeados, mide $2-5 \mu \mathrm{m}$ de largo y $0.5 \mu \mathrm{m}$ de ancho. Cuando B. mallei es cultivada en medios adecuados por 1 o 2 días, el organismo produce pequeñas colonias amorfas y traslúcidas (Al-Ani \& Roberson, 2007).

El modo de transmisión del muermo en equinos ha sido debatido por varios años, pero se ha acordado que generalmente la transmisión ocurre por ingestión (Al-Ani \& Roberson, 2007). Brown (2002), indica también se puede diseminar la enfermedad mediante la aspiración del organismo; Et Alahan et al. (1998) menciona que la contaminación de heridas cutáneas, también pueden causar la enfermedad.

Utensilios, agua y alimentos contaminados pueden jugar un rol en la transmisión de la enfermedad. Burkholderia mallei puede ser aislada desde el estiércol y la piel de los animales infectados. Factores de riesgo para la transmisión incluyen condiciones poco sanitarias y establos atestados donde las secreciones infecciosas pueden ser pasadas directamente desde un animal a otro, o indirectamente por el uso de instrumentos (Al-Ani \& Roberson, 2007).

La mosca doméstica (Musca domestica) puede jugar un rol muy importante en la diseminación del muermo (Al-Ani \& Roberson, 2007).

Caballos de cualquier raza y sexo son susceptibles a la enfermedad, pero los animales de más de dos años son más susceptibles a la forma cutánea. La enfermedad se puede desarrollar durante cualquier estación; la incidencia es alta entre caballos expuestos a clima frío intenso. Los caballos más susceptibles son 
aquellos que reciben una nutrición inadecuada y se mantienen bajo condiciones ambientales pobres (Al-Ani \& Roberson, 2007).

El periodo de incubación puede ser de semanas a meses (Brown, 2002). Luego de un lapso de aproximadamente dos semanas, los animales afectados usualmente tienen septicemia y fiebre alta $\left(41^{\circ} \mathrm{C}\right)$ y, posteriormente, descarga nasal mucopurulenta y espesa y signos respiratorios. La enfermedad crónica es más frecuente en caballos que están en contacto con burros y mulas que desarrollan la forma aguda de la enfermedad. Aparentemente los animales recuperados permanecen como portadores (Manual Merck, 2008; Al-Ani \& Roberson, 2007).

Al-Ani \& Roberson (2007), indican que el muermo en equinos puede ser clasificado en cuatro formas: cutáneo, pulmonar, nasal y portador asintomático. La forma cutánea puede resultar de una injuria de la piel o ser manifestación secundaria de la forma respiratoria.

Las lesiones cutáneas incluyen úlceras en la mucosa nasal que se expanden con rapidez o nódulos en la piel de la región distal de las extremidades o de las paredes del abdomen. En los casos crónicos, las úlceras cicatrizan produciendo las características cicatrices estrelladas. Los nódulos subcutáneos se ulceran y rompen para luego descargar un exudado espeso, marrón y similar a la miel. Se observan cordones linfáticos y los linfonódulos regionales pueden estar aumentados de tamaño y drenar, los miembros posteriores se involucran con mayor frecuencia. Los signos agudos de enfermedad sistémica incluyen fiebre, tos, descarga nasal, respiración laboriosa y, a menudo, muerte. En las infecciones crónicas se evidencia tos, respiración laboriosa, rinorrea, linfonódulos mandibulares aumentados de tamaño y frecuentes brotes de epistaxis, con o sin desarrollo de lesiones cutáneas (Colahan, 1998; Al-Ani \& Roberson, 2007). En la forma cutánea el hígado y bazo pueden mostrar lesiones nodulares típicas (Manual Merck, 2008).

El diagnóstico en áreas del mundo donde ésta enfermedad es endémica es fácil de realizar mediante los hallazgos clínicos y patológicos. Los nódulos, úlceras, formación de cicatrices y condición debilitada pueden proveer evidencia suficiente para el diagnóstico, con confirmación por cultivo bacteriano (Brown, 2002; Manual Merck, 2008). El examen histopatológico revela una dermatitis 45 supurativa a piogranulomatosa. Puede ser nodular o difusa y los microorganismos se pueden visualizar con la tinción de Gram. Los microorganismos se pueden aislar al cultivar el pus de los nódulos abiertos (Colahan et al., 1998). También se puede realizar la prueba de la maleina y pruebas serológicas (Al-Ani \& Roberson, 2007).

La prueba de la maleina produce una reacción inmune mediada por células, se realiza inyectando 0,1 $\mathrm{mL}$ de maleina dentro de la piel y cerca del borde del párpado inferior. Una reacción positiva usualmente se desarrolla en 48 a 72 horas y se caracteriza por edema marcado del párpado con blefarospasmo y conjuntivitis purulenta severa. La prueba de la maleina tiene un valor predictivo positivo de $92 \%$ en los casos agudos y crónicos y un valor predictivo negativo de $96 \%$ en casos avanzados (Al-Ani \& Roberson, 2007).

El diagnóstico diferencial de la forma cutánea crónica incluye: linfangitis ulcerativa, histoplasmosis (linfangitis epizoótica), papera equina, esporotricosis, micobacteriosis, actinomicosis y nocardiosis. La forma aguda se debe diferenciar de la melioidosis (Colahan et al., 1998; Al-Ani \& Roberson, 2007).

La terapia antibiótica óptima para la enfermedad aún no ha sido determinada. El tratamiento sistémico de los caballos infectados con antibióticos, incluyendo penicilina y estreptomicina, es usualmente inefectivo en el control de la enfermedad. Aunque hay alguna evidencia contradictoria para ampicilina, gentamicina y tetraciclina, hay evidencia acumulada que dice que enrofloxacino, eritromicina, ampicilina, sulfonamidas, gentamicina y tetraciclina podrían ser efectivos contra B. mallei. Esta evidencia emerge por estudio de sensibilidad in-vitro y cerdos de Guinea infectados experimentalmente (Al-Ani \& Roberson, 2007).

Doxiciclina, ceftrazidima, gentamicina, estreptomicina y combinaciones de sulfazina o sulfamonometoxina con trimetoprim han sido eficientes en la prevención y tratamiento de muermo experimental (Manual Merck, 2008).

No se recomienda el tratamiento de estos animales ya que puede predisponer a un estado de portador. Para controlar la enfermedad se sugiere realizar las pruebas diagnósticas y la eutanasia para los positivos, teniendo cuidado de proteger a las personas que manejan los animales. Es esencial efectuar la desinfección y la buena sanidad, con destrucción de la cama y los materiales aptos para albergar a los microorganismos (Colahan et al., 1998). 
Enfermedades caracterizadas por edema o inflamación difusos.

Dermatofilosis

La dermatofilosis (estreptotricosis) es una dermatitis exudativa crónica o aguda (Colahan et al., 1998), con formación de costras, que afecta principalmente a equinos, bovinos, ovinos, caprinos, a algunos reptiles y rara vez a las personas. Usualmente los casos humanos reportados están asociados con manipulación de animales enfermos. La enfermedad ha sido registrada en camellos, búfalos, burros, gatos, perros y animales silvestres. Está causada por un actinomiceto, el Dermatophilus congolensis. Es también llamada erróneamente dermatitis micótica (Vadillo, 2002; Awad et al., 2008; Manual Merck, 2008).

Aunque la enfermedad está ampliamente difundida por todo el mundo, su importancia es mayor en los países tropicales principalmente en países africanos y en áreas geográficas con temporadas de alta pluviometría, como pueden ser las zonas de influencia monzónica y se ha extendido en Europa, Australia y América (Awad et al., 2008; Vadillo, 2002).

D. congolensis es una bacteria grampositiva de talo filamentoso y ramificado. Los filamentos maduros, de grosor variable, se dividen por tabiques transversales hasta formar un denso empaquetamiento de cuerpos cocoides, dispuestos en 2 a 8 hileras paralelas que, en presencia de suficiente humedad, se liberan y transforman en zoosporas móviles, las formas infectantes. Es anaerobio facultativo y carboxifilco, crece bien en medios enriquecidos, en los que suele formar colonias rugosas firmemente incrustadas en el medio (Vadillo, 2002). Las colonias son generalmente naranja claro o amarillentas, pero 47 ocasionalmente pueden aparecer variantes blancas o grises; son catalasa positivos y tienen metabolismo fermentativo (Scanlan, 1991).

Se desconoce cuál es el hábitat normal de este microorganismo, pero se piensa que existe en un estado latente en animales portadores hasta que las condiciones son óptimas para su proliferación (Scanlan, 1991). No se sabe si los animales portadores actúan como reservorio de la infección para otros animales. Los microorganismos pueden permanecer en costras durante 42 meses. La bacteria solo se ha aislado del integumento de los animales. Probablemente lleva una existencia saprofítica en el suelo; sin embargo, los intentos por aislarlos del suelo han sido infructuosos. Los animales asintomáticos con infección crónica se consideran el reservorio primario. No existe predilección aparente por raza, sexo o edad (Reed et al., 2005; Colahan et al., 1998; Manual Merck, 2008; Smith, 2002).

La alteración también se conoce como - escaldadura o dermatitis de la lluvia (Colahan et al., 1998), - rain rot , - dew poisoning (Kobluk et al., 1995). Las lluvias fuertes o el rocío enérgico con agua son particularmente eficaces para ablandar los estratos superficiales de la piel y permitir la infección. La piel embebida en agua es más fácil de erosionar y es probable que sea más susceptible a la infección. El desarrollo de las lesiones depende de la humedad crónica y de la lesión cutánea. $D$. congolensis es visto usualmente durante los meses de otoño e invierno, correspondiendo a la lluvia. El microorganismo no puede atravesar la piel intacta y sana, y se requiere humedad para la liberación de las zoosporas (Reed et al., 2005; White, 2005). Los ataques concurrentes de ectoparásitos, en especial las moscas picadoras y garrapatas constituyen un trauma suficiente. La dermatofilosis se puede diseminar utilizando peladoras y equipos de cortes de pelos contaminados o por lesiones húmedas, que producen la liberación de las zoosporas infectivas. El estrato córneo intacto y los lípidos de la superficie son barreras importantes contra la infección por D. congolensis (Colahan et al., 1998; Smith, 2002; White, 2005).

Las lesiones costrosas exudativas tienden a aparecer sobre el dorso, el área glútea, la cara, el cuello, el hocico y la parte distal de las extremidades (Reed et al., 2005; Smith, 2002); y pueden dar la impresión que grandes gotas han marcado la piel, causando un exudado que amontona el pelo en forma de placas. Estas placas tienen, por lo general, menos de $2 \mathrm{~cm}$. de diámetro, pero pueden coalescer cubriendo grandes áreas, (Colahan et al., 1998). Un efecto de fotosensibilización aparente puede causar eritema en caballos con marcas faciales blancas (Kobluk et al., 1995; Colahan et al., 1998). Los signos clínicos de la dermatofilosis se pueden desarrollar en 24 horas. La enfermedad tiene una orientación folicular, y las lesiones aparecen como costras y matas de pelo húmedo que se asemejan a pequeños pinceles (Reed et al., 2005; Smith, 2002; White, 2005). Los animales pueden tener tendencia a tocarse en los estadios agudos, pero no son lesiones pruriginosas. La eliminación del pelotón de pelos revela una lesión húmeda, rosada, hemorrágica (Colahan et al., 1998; Smith, 2002). La superficie profunda cóncava de la costra está húmeda, con un grado variable de pus amarillo verdoso o un exudado gris gelatinoso; en las lesiones viejas puede no haber exudado. 
Cuando se eliminan las costras en los casos iniciales, el animal puede manifestar dolor (Colahan et al., 1998; White, 2002).

La dermatofilosis puede afectar las extremidades, en especial si el caballo se mantiene en lugares húmedos y si los miembros presentan traumatismos, como los producidos por patadas o en las pistas (White, 2005; Colahan et al., 1998).

Los cúmulos de pelos, unidos en su base para formar una costra con una superficie profunda cóncava cubierta con exudado, son un hallazgo casi diagnóstico de dermatofilosis (Colahan et al., 1998; Smith, 2002).

Lesiones similares pueden ser vistas con la dermatofitosis (en especial con Microsporum gypseum), la foliculitis bacteriana debida a Staphylococcus aureus, o a Corynebacterium pseudotuberculosis, las infecciones virales y el pénfigo foliáceo (Colahan et al., 1998).

El diagnóstico presuntivo se basa en los antecedentes, examen físico. El diagnóstico definitivo se realiza mediante cultivo bacteriano y examen de laboratorio de las costras. Es necesario realizar un cultivo para hongos, a los efectos de descartar una dermatofitosis. Los frotis con muestras de pus o las improntas realizadas con la cara profunda de las costras son buenas fuentes para aislar e identificar el Dermatophilus (Manual Merck, 2008; Colahan et al., 1998).

Las preparaciones realizadas a partir de muestras de la cara profunda de las costras en los casos agudos contienen a menudo microorganismos en cultivo puro. En los casos crónicos el examen del cultivo no suele ser satisfactorio debido a la alta contaminación por los invasores secundarios (Manual Merck 2008; Colahan et al., 1998).

El examen de las biopsias revela foliculitis, dermatitis pustular intraepidérmica y dermatitis perivascular. Los neutrófilos son las principales células inflamatorias. A menudo, los queratinocitos presentan edema intracelular; la paraqueratosis y la ortoqueratosis son hallazgos frecuentes dentro de la costra y los folículos pilosos (Colahan et al., 1998).

El aspecto más importante de la terapia involucra la remoción de los factores predisponentes a la infección. Los parásitos externos que causan daño de la piel y transmisión de la bacteria deben ser eliminados. Los animales infectados clínicamente deben ser aislados. Las costras deben ser eliminadas apropiadamente para evitar la contaminación del ambiente y se debe desinfectar el área donde los animales se han mantenido (Manual Merck, 2008; Smith, 2002).

Es difícil evaluar el tratamiento, ya que muchos caballos se recuperan en forma espontánea en unas 4 semanas (Colahan et al., 1998); el tratamiento en este caso está indicado debido a que las lesiones interfieren con el uso y son dolorosas (Manual Merck, 2008). El éxito del tratamiento requiere mantener al animal seco y protegido de la picadura de insectos, eliminación y desecho apropiado da las costras (Colahan et al., 1998).

En los casos graves o crónicos, administración sistémica de penicilina procaínica (22000 UI/Kg., IM) y dihidroestreptomicina (11 mg/Kg. /2 veces /día, durante 5 a 7 días) o estreptomicina (22mg/kg) (Manual Merck, 2008; Colahan, 1998; White, 2005; Smith, 2002). Si estas fallan se puede emplear la combinación penicilina-estreptomicina por 5 días, o una sola inyección de oxitetracilina de larga acción (20 mg/kg) (Manual Merck, 2008).

Las lesiones pueden ser remojadas y removidas suavemente. La terapia tópica con shampoo antibacteriano es efectiva como tratamiento adyuvante. Se recomienda Clorhexidina y peróxido de benzoilo. Insecticidas aplicados externamente son usados para controlar insectos mordedores (Manual Merck, 2008). En los casos leves, solo puede requerirse la terapia tópica. Las soluciones de sulfuro de cal (2-5\%), captan (3\%) o povidona yodada (1:10) se pueden aplicar con atomizadores o mojando la zona 1 vez por día durante 5 a 7 días y luego continuar en forma semanal hasta que la remisión clínica sea evidente. En las lesiones localizadas, el uso tópico de una solución acuosa de cloranfenicol al 0,25\% da buenos resultados (Colahan et al., 1998).

Las lesiones secas y duras que se fracturan y fisuran responden bien a las cremas y ungüentos que contienen antibióticos y corticoides, como la neomicina o la hidrocortisona. Muchas lesiones húmedas pueden responder mejor a los astringentes. Debe recordarse que las personas pueden padecer esta infección a causa del contacto con animales y costras infectadas (Colahan et al., 1998).

Foliculitis estafilocócica 
Foliculitis es un término histológico que indica inflamación del folículo piloso. Furunculosis es la ruptura del folículo piloso. Varios agentes infecciosos, incluyendo bacterias, dermatofitos, y parásitos pueden causar foliculitis. Foliculitis es frecuentemente utilizado como un término clínico que implica enfermedad bacteriana de la piel, sin embargo, este uso no es enteramente correcto (Kobluk et al., 1995). Smith (2002) define la foliculitis como una inflamación del folículo piloso secundaria a infección bacteriana. La foliculitis estafilocócica, causada por Staphylococcus aureus, es el tipo más común de foliculitis bacteriana en los caballos (Colahan et al., 1998); también S. Intermedius puede ser aislado. Corynebacterium pseudotuberculosis, C. equi, Streptococcus zooepidermicus pueden también causar foliculitis y en raras ocasiones otras bacterias como Bacillus spp. (Kobluk et al., 1995; Smith, 2002). White y Yu (2006), indican que en un estudio se aislaron S. hyicus.

Se produce con mayor frecuencia en el verano (Colahan et al., 1998; White \& Yu 2006) y primavera (Kobluk et al., 1995). Se piensa que el trauma cutáneo por mordedura de insectos, heridas con clavos, el estrés, calor, factores, por trabajo pesado, pobre higiene, mal manejo y humedad pueden provocar su desarrollo (Smith, 2002; Colahan et al., 1998; Kobluk et al., 1995; White \& Yu, 2006). En los animales bien cuidados que son bañados luego del trabajo se observan escasas infecciones. El hecho de refregarse la cola debido a causas variables contribuye con las lesiones en esa zona. La foliculitis estafilocócica es también una de las causas de la dermatitis de la cuartilla (Colahan et al., 1998).

Las lesiones se presentan en el tórax, la cuartilla, el área de la silla, la región lumbar y/o cola (Smith, 2002; White \& Yu, 2006; Kobluk et al., 1995, Colahan et al., 1998). La lesión primaria es una pápula; ocasionalmente pústula; centrada en el folículo piloso que causa la elevación del pelo, dichas pápulas miden entre 2-3mm (Kobluk et al., 1995; Colahan et al., 1998; Smith, 2002) y, por lo general, es bastante dolorosa a la palpación y está muy inflamada interfiriendo con el trabajo (White \& Yu, 2006). Este cuadro puede continuar con la involución de la pápula, la formación de las pústulas o el agrandamiento de la lesión con ulceración o drenaje y eventual pérdida de pelo (Kobluk et al., 1995; Colahan et al., 1998). Cuando se forman las pústulas y luego se rompen, el exudado se seca creando costras o placas que incorporan el pelo y las lesiones se visualizan con facilidad (Colahan et al., 1998; White \& Yu, 2006). Durante la fase de cicatrización, las lesiones se aplanan y se desarrollan áreas circulares de alopecia y descamación. Las pústulas pueden extenderse hacia la dermis y el subcutáneo produciendo una inflamación más grave denominada furunculosis (Colahan et al., 1998). En esta situación se desarrollan nódulos, úlceras, costras y fístulas; las que se encuentran más a menudo en el cuello, lados del tórax, superficie interna del muslo o prepucio 52 (White \& Yu, 2006). Estas lesiones profundas dan lugar a cicatrices y pérdida de pigmento (Colahan et al., 1998).

En lesiones localizadas en la cola, las pústulas se originan en la superficie dorsal del apéndice coccígeo. El desarrollo de un prurito intenso conduce a la automutilación y lleva a una condición crónica que responde mal al tratamiento. La descarga desde la ruptura de las pústulas causa el aglutinamiento de los pelos largos de la cola. Las pústulas cicatrizan y se rompen continuamente (Colahan et al., 1998).

El diagnóstico diferencial incluye la foliculitis corinebacteriana, dermatofilosis, dermatofitosis, demodicosis y dermatitis por Pelodera (Colahan et al., 1998; Kobluk et al., 1995). En la forma coccígea hay que considerar, como probables alteraciones primarias, el rascado por oxiuriasis, sarna, pediculosis, hipersensibilidad por picadura de insectos, alergia alimenticia y vicios de establo (Colahan et al., 1998). Los raspados de piel, tinciones Gram del contenido pustular, los cultivos bacterianos y fúngicos y frotis por impresión son necesarios para llegar a un diagnóstico definitivo en los caballos afectados (Colahan et al., 1998; Kobluk et al., 1995; Smith, 2002). Se deben examinar las preparaciones a partir de las costras en busca de Dermatophilus (Colahan et al., 1998). El diagnóstico se confirma con el examen histológico de las biopsias de piel y cultivo bacteriano (Kobluk et al., 1995).

En ocasiones las biopsias revelan perifoliculitis, foliculitis y furunculosis. Es común que se presenten muchos eosinófilos asociados con las lesiones de furunculosis (Colahan et al., 1998).

Los casos leves de foliculitis pueden curarse sin la aplicación de tratamientos (Smith, 2002). Las infecciones leves o que no progresan a furunculosis pueden responder a los champúes de yodóforos, clorhexidina (Colahan et al., 1998), betadina y combinaciones azufre-ácido salicílico (Kobluk et al., 1995), ungüentos con mupirocina $2 \%$ o cremas de plata-sulfadiazina (Smith, 2002; White \& Yu, 2006), junto con la prevención de nuevos traumas (Colahan et al., 1998). El antibiótico usualmente utilizado para muchas infecciones bacterianas de la piel en el equino es trimetoprim-sulfonamida oral ( $30 \mathrm{mg} / \mathrm{kg}, \mathrm{P} .0$. cada $12 \mathrm{hrs}$ 
por 2 a 6 semanas, alargar en caso de infecciones profundas). En casos de resistencia de Staphylococcus spp. a trimetoprim-sulfonamida, enrofloxacino (7.5 mg/kg P.O.; una vez al día) puede ser usada. El uso de enrofloxacino en animales jóvenes (menores de 2 años) debe ser evitado porque produce daño en el cartílago articular (White \& Yu, 2006).

Baños diarios con champúes antibacterianos y reposo también están indicados. Con el tratamiento, el curso de la enfermedad puede ser de 2 semanas. La aplicación de los antibióticos debe continuar durante 7 a 14 días después de la resolución clínica (Colahan et al., 1998).

Foliculitis corinebacteriana

La foliculitis y furunculosis (equine contagious acne, Canadian horsepox y equine contagious pustular dermatitis) causada por corinebacterias es la forma de enfermedad menos importante, que probablemente representa una infección secundaria por $C$. pseudotuberculosis de patologías preexistentes como seborréa o dermatitis. Aparece comúnmente en primavera y verano; y puede ser provocada por varias formas de trauma cutáneo. Las lesiones tienden a desarrollarse en los puntos de contacto con arneses y otros aparejos. Se puede diseminar a través del contacto con equipamiento contaminado. Las lesiones características son pequeños nódulos dolorosos que crecen y forman pústulas que luego se rompen y descargan material purulento blanco verdoso. Aparentemente no existe predilección por raza, sexo o edad. Estas lesiones usualmente resuelven espontáneamente, pero pueden ocasionalmente provocar úlceras en el sitio de infección (Baird \& Fontaine, 2007; Scott \& Miller, 2003).

El diagnóstico y tratamiento son similares a los de la foliculitis estafilocócica. Las lesiones que coalescen para desarrollar úlceras, responden menos a la antibióticoterapia y pueden necesitar la resección quirúrgica, con cicatrización por segunda intención (Colahan et al., 1998)

\section{Discusión}

Según Paterson (2003); en la práctica equina las enfermedades bacterianas de piel son comúnmente encontradas y pueden ser generalizadas. Monteiro et al. (2008), señalan que, de todas las enfermedades de los equinos, las dermatopatías están entre las más difíciles de diagnosticar y tratar, debido a la semejanza de los cuadros clínicos sumado a la falta de conocimiento técnico específico y la interacción de estos.

Es necesario tener una pauta que nos permita diferenciar un proceso dermatopatológico local de uno sistémico. Esta pauta debe incluir el historial del animal, la anamnesis individual y grupal; y examen físico completo; con una descripción detallada de las lesiones y hallazgos relevantes. Así también, es necesario realizar exámenes complementarios, con el fin de determinar el agente etiológico específico causante de la dermatopatía, para luego instaurar el tratamiento adecuado, y tomar los resguardos necesarios para impedir o disminuir la diseminación del agente etiológico y impidiendo la propagación de la patología.

Las enfermedades bacterianas de piel son causadas más a menudo por Staphylococcus sp, C. pseudotuberculosis o Dermatophilus congolensis (White; 2005).

Monteiro et al. (2008) realizaron un estudio en la zona de Mata Mineira, Brasil; en 26 caballos de ambos sexos y edades comprendidas entre dos semanas y 20 años; de los cuales cuatro presentaban dermatofilosis (15.4\%) y tres de foliculitis bacteriana (11.5\%); Szczepanik et al. (2006); describen un caso de dermatofilosis en Polonia y en su investigación señalan, además, que la enfermedad estaría presente en Estados Unidos, Nueva Zelanda, Israel y también en Islandia. Awad et al. (2008); también reportan casos de dermatofilosis en Egipto, en un $9,6 \%$ de un total de 8 equinos.

En Chile existen reportes de dermatofilosis en equinos; aunque Arancibia (2000) y Pérez (1997) describen la presencia de Dermatophilus congolensis principalmente en terneros.

Corynebacterium pseudotuberculosis es un agente presente en muchos países de Europa, América, África y Asia, en concordancia con zonas de alta producción de ovinos, caprinos y equinos. También es diagnosticada en Canadá y Japón, donde la cría de 55 pequeños rumiantes no es tan relevante (Nachon \& Bosisio; 2005). Estevao et al. (2006) indican que C. pseudotuberculosis es un microorganismo cosmopolita y que afecta a los equinos en zonas como California o Texas donde la cría de caballos es importante; Doherr 
(1998) indica que los abscesos profundos provocados por C. pseudotuberculosis es una de las causas de enfermedad infecciosa más común y económicamente importante en California.

Hall et al. (2001); demuestran la presencia de abscesos pectorales provocados por $C$. pseudotuberculosis en equinos de Colorado, Estados Unidos

En nuestro país Gädicke et al. (2008) señalan que en el año 1998 durante los meses estivales se denunciaron al Servicio Agrícola y Ganadero (SAG) de la Provincia de Nuble, gran cantidad de casos de equinos con inflamación principalmente en el área pectoral, glándula mamaria o prepucio, con abscedación de algunas de ellas; desde éstas lesiones se aisló C. pseudotuberculosis. De acuerdo a White (2005); la infección puede ser contraída en áreas donde es común la linfoadenitis caseosa (L.A.C) en ovejas; Estevao et al. (2006) menciona que se notificaron casos de linfoadenitis caseosa en países dedicados a la cría de pequeños rumiantes (ovinos y caprinos) tales como: Canadá, Australia, Francia, Holanda, Nueva Zelanda, Estados Unidos, Brasil, Suiza, Uruguay, Venezuela, Turquía, Cuba entre otros y ha sido recientemente comunicada en países como Dinamarca, previamente libres de linfoadenitis caseosa.

En nuestro país L.A.C se examinó un total de 1.397 ovinos de distintas categorías (corderos, borregas, ovejas, capones y carneros), edades y procedencias; en base a los hallazgos de lesiones macroscópicas de los nódulos afectados y a sus cultivos positivos a C. pseudotuberculosis, concluyendo que la enfermedad linfoadenitis caseosa se encuentra presente en la XI Región (Tadich et al.; 2005).

De los agentes etiológicos que están presentes en las dermatopatías también destaca la presencia de B. abortus; Weese (2002) indica que la presencia de mal de la cruz ocasionado por esta bacteria varía según la región geográfica, siendo alta en Texas y baja en Nueva York. Gore et al. (2008) señalan que ahora es rara la presencia de la patología en Estados Unidos y Canadá, debido a los exitosos esfuerzos por erradicar la enfermedad en bovinos, aunque aún existe ésta patología en México y el Caribe.

Refai (2002); indica que fue descrita brucelosis en 5,8\% de la población equina estudiada en Egipto; Doumbia (2008), reporta la enfermedad en 33 burros que representan el 35\% de la población de équidos que se presentaron a la Spana Clinic en Mali. Si bien en nuestro país no se ha descrito la enfermedad en equinos, López et al. (1998) y Felmer et al. (2009) describen la presencia de brucelosis en predios lecheros bovinos de la VIII y IX región respectivamente, lo que indica que el agente etiológico del Mal de la Cruz está presente en nuestro país Burkholderia (antiguamente Pseudomonas) mallei; agente etiológico de muermo; ha sido reportada en años recientes en Irak, Turquía, Vietnam, Corea, Italia, Rusia, Pakistán, India, Mongolia, China, Brasil y Emiratos Árabes Unidos (Manual Merck, 2008; Al-Ani \& Roberson, 2007).

El muermo ha sido efectivamente erradicado en Norte América y el Oeste de Europa en la década de 1950; no existen casos reportados en más de 60 años en Estados Unidos (Bondi \& Goldberg; 2009)

El resto de los microorganismos productores de patologías dérmicas en equinos forman parte de la flora normal de la piel y mucosas; por lo que es posible afirmar que cualquier patología de la piel o alteración del estado general del animal puede provocar la entrada en la piel de este y provocar los signos dermatológicos de enfermedad.

Se podría concluir que las patologías dérmicas son comunes a nivel mundial y son de importancia debido a que pueden afectar el buen desempeño de los equinos. La mayoría de las dermatopatías en equinos son provocadas por bacterias que son parte de la flora normal de la piel, desarrollándose la enfermedad por un mal manejo y manutención de los animales; y de los elementos de uso periódico en ellos. Para lograr un buen diagnóstico y tratamiento de las patologías dérmicas es necesario realizar un buen examen clínico del equino y emplear lo métodos complementarios adecuados. Es necesario realizar estudios de las dermatopatías bacterianas que afectan a los equinos a nivel nacional para determinar la presencia de éstas, ya que existe escasa información en nuestro país y es necesario disponer de una mayor variedad de Antimicrobianos de uso en dermatopatías equinas en Chile.

\section{Bibliografía}

Al-Ani, F K.,\& J Roberson. "Glanders in horses: A review of the literature.Veterinarski Arhiv 77 2007: 203-18. Arancibia A. R. 2000. Principales patologías de terneros y causas de aborto en bovinos diagnosticadas en el instituto de patología animal de la Universidad Austral de Chile periodo 1990 - 1999. Memoria de título. Escuela de Medicina Veterinaria, Universidad Austral de Chile, Chile. 
Sustainability, Agri, Food and Environmental Research 3(4), 2015: 30-53 ISSN: 0719-3726

Awad, W S., Nadra-Elwgoud, M I. Abdou, A. \& A. El-Sayed 2008. Diagnosis and Treatment of Bovine, Ovine and Equine Dermatophilosis. Journal of Applied Sciences Research $4: 367-74$.

Baggot, D J 2001. The Physiological Basis of Veterinary Clinical Pharmacology. Cornwall: Blackwell Science Ltd, 2001. Print.

Baird, G J., \& M.C. Fontine. 2007 Corynebacterium pseudotuberculosis and its Role in Ovine Caseous Lymphadenitis." J. Comp. Path 137: 179-210.

Biberstein, L. E. \& Yuang C. Zee. 1994. Tratado de microbiología veterinaria. Zaragoza: Acribia. Print.

Bondi, S. K. \& Goldberg J.B. "Strategies toward vaccines against Burkholderia mallei and." Expert Rev Vaccines 7.9: 1357-65.

Brown, C. 2002. "Foreign animal diseases with equine potential." Proceedings of the Annual Convention of the AAEP $48: 16-20$

Carter, G.R., Payne, P.A.; Davis, E. Preface. In: Carter G.R., Payne P.A. \& Davis E. 2007 (Eds.), A Concise Guide to the Microbial and Parasitic Diseases of Horses. http://www.ivis.org/advances/carter _equine/th preface/chapter.asp?LA=1 (visited 30 june 25th 20014)

Colahan, P T., I G. Mayhew, A M. Merritt \& J N. Moore. 1998. Medicina y cirugía equina. 4th ed. Vol. 2. Buenos Aires: Intermedica. 1447-593 pp Print. 2 vols.

Cowell, R I., R D. Tyler \& J H. Meinkoth. 2003. Citología y hematología diagnostica en el perro y gato. 2nd ed. Barcelona: Multimedica, 456-4460 pp

Kahn, C M., S line \& S E. Aiello. 2009 eds. The Merck Veterinary Manual. 9th ed. New Jersey: Merck \& Co., Inc. http://www.merckvetmanual.com/mvm/index.jsp?cfile=htm/present/mvm_about.htm $>$ ( visited 30 th november 2014).

Doherr, M G., T E. Carpenter, K. M. Hanson, W D. Wilson et al. 2009. "Risk factors associated with Corynebacterium pseudotuberculosis infection in California horses ." Preventive Veterinary Medicine 35.4 229-3. http://www.sciencedirect.com/science?_ob=ArticleURL\&_udi=B6TBK-3T176K4- (visited 20 mai 2014) Doumbia, A. 2008. "Fistulous withers: a major cause of morbidity and loss of use amongst working equines in west Africa. An evaluation of the aetiology and treatment of 33 cases in Mali". Proceedings of the 10th International Congress of World Equine Veterinary Association- Moscow; Russia. http://www.ivis.org/proceedings/weva/2008/shortcom9/1.pdf?LA=1> ( visited 20 th february 2014)

Estevao, B S., A Gallardo, A Hablaos, J. J. Odor et al. 2006 "Actualización sobre linfoadenitis caseosa el agente etiológico y la enfermedad.

<http://www.produccion-animal.com.ar/sanidad_intoxicaciones_metabolicos/infecciosas/ovinos/01-

linfoadenitis_caseosa.pdf $>$. ( visited 10 mai 2014)

Felmer, A R., J Zuñiga, A Lopez y H Miranda. 2009. Prevalencia y distribución espacial de brucelosis, leucosis bovina, diarrea viral bovina y rinotraqueítis infecciosa bovina a partir del análisis ELISA de estanques prediales en lecherías de la IX."

http://www.scielo.cl/scielo.php?pid=S0301-732X2009000100003\&script=sci_arttext>.

Gädicke, P, G Azócar, M Ocaña. 2008. "Descripción de casos de absceso pectoral crónico y análisis de algunas variables asociadas a su presentación en equinos de la Provincia de Ñuble, Chile." http://www.scielo.cl/pdf/amv/v40n1/art05.pdf> ( visited 7 mai 2014)

Gartner, L Y L Hiatt. 2008. Texto Atlas de Histología. 2nd ed. Mexico: McGraw-hill Interamericana, 2002. Print. 458-478 pp.

Gore, T, P Gore y J M. Giffin. 2008. Horse Owner's VETERINARY Handbook . 3rd ed. NEW JERSEY: Wiley Publishing Inc,. 345-350 pp.

Hall, K B., B McCluskey, and W Cuningham. 2001. "Corynebacterium pseudotuberculosis infections (pigeon fever) in horses in western Colorado; an epidemiological investigation." journal of equine veterinary science 21-284-86.

Harvey, R G. y P. J.2001. McKeever. Manual Ilustrado de Enfermedades de la piel en perro y gato. N.p.: GRASS, 2001.34-50 pp.

Junqueira, L C. y J Carneiro. 2000. Histologia básica. 5th ed. Barcelona: Masson. 61 pp.

Kobluk, C N., T R. Ames y R J. Geoor. 1995. The horse diseases \& clinical management . Vol. 1. PHILADELHIA: SAUNDERS,.49-59 pp. Print. 2 vols.

Lloyd, D. H., Littlewood J. D., Craig J. M. y Thomsett L. R.2003. Practical Equine dermatology Oxford: Blackwell science, 459-490 pp. 
Lopez, J. y Best, A. 1998. Diagnóstico de brucelosis bovina en leche por el Ring Test y ELISA en lecherías de la provincia de Ñuble (VIII Región).http://www.scielo.cl/scielo.php?script=sci_arttext\&pid=S0301732X1998000100015\&lng=es\&nrm=iso>( Visited 18 mai 2015).

Miller, M A., Fales W H., Tyler J W., Suedmeyer WM K.2001. "Pulmonary botryomycosis in a Scottish Highland steer." Journal of Veterinary Diagnostic Investigation 13 (2001): 74-76.

Monteiro, G A., M V. de Souza, L Gonçalves, C Balbi e rocha et al. 2008. "Diagnostico das dermatoses alopécicas multifocais em equinos da zona da Mata Mineira do Brasil." Vet. e Zootec 15.1 139-49

Muller, G H., R W. Kirk y D W. Scott. 1993. Dermatología en Pequeños Animales. 4th ed. Buenos Aires: Intermedica. 212-120 pp.

Nachon H., Bosisio C. ; Enfermedades Infecciosas de los Equinos; 2ạ edición; Área Salud y Producción Equina Facultad de Veterinaria Universidad de Buenos Aires. http://www.produccionanimal.com.ar/produccion_equinos/curso_equinos_l/60-prevencion_infecciosas.pdf]( visited 8th mai 2014) Paterson, Sue. 2003. "Treatment of skin disease in the horse 2. Topical therapy." In Practice 25: 146-50 Pérez González M. A. 1997. Estudio anátomo e histopatológico de bazo y timo de terneros de crianza artificial, muertos en el primer mes de vida. Memoria de título. Escuela de Medicina Veterinaria, Universidad Austral de Chile, Chile.

Prescott, J F., J D. Baggott y R D. Walker.2001. Terapéutica antimicrobiana en medicina veterinaria. 3rd ed. Buenos aires: intermedica. 23-28 pp.

Radostis, O M., C. C. Gay, D. C. Blood y K W. Hinchcliff. 2002 Tratado de las enfermedades del ganado bovino, ovino, porcino, caprino y equino. 9th ed. Vol. 1. Madrid: McGraw-hill Interamericana.56-79 pp. Print. 2 vols.

Reed, S M., W M. Bayly y D C. Sellon. 2005 Medicina interna equina. 2nd ed. Vol. 1. Buenos Aires: Intermedica, 2005. 890-900 pp. Print. 2 Vols.

Rejas J., Dermatología clínica veterinaria. http://www3.unileon.es/personal/wwdmvjrl/index.html ( visited 2th mai 2014)

Ruiz, J. Propedéutica Dermatológica Veterinaria 2005. La Habana: Universidad de Granma Facultad de Medicina Veterinaria. www.monografias.com/trabajos20/dermatologia-veterinaria/dermatologiaveterinaria.shtml?monosearch> ( visited 5 th june 2015)

Santamaria V., Araceli A. 2002. "Flora cutánea como protección y barrera de la piel normal." Rev Cent Dermatol Pascua 11: 18-21.

Sevilla Agirregomoskorta, I. 2007 Caracterización molecular, detección y resistencia de -Mycobacterium avium subespecie - Paratuberculosis. Tesis doctorales. Universidad del País Vasco. [http://www.habe.euskadi.net/s234728/es/contenidos/informe_estudio/tesis_doctorales/es_agripes/adjun tos/tesis_doctoral59.pdf]. (visited 5 mai 2014).

Scanlan, C M.1991. Introducción a la bacteriología veterinaria. Madrid: Acribia, 1991.99 p

Scott, D. W. 2007. "Cutaneous Bacterial Pseudomycetoma (Botryomycosis) in Dogs: Two New Cases Reports and a Review of the Literature." The Japanese Journal of Veterinary Dermatology 13 : 135-40.

Scott D. W.y Miller W. H.. Equine dermatology. Missouri: Elsevier science, 2003. Print.

Sørum, H y M Sunde. 2001. "Resistance to antibiotics in the normal flora of animals." Vet. Res 32 : 227-41.

Szczepanik, M, M Golyński, D Pomorska, P Wilkolek et al. 2006. "DERMATOPHILOSIS IN A HORSE - A CASE REPORT." Bull Vet Inst Pulawy 50 : 619-22.

Tadich, N; Alvarez, C; Chacon, T y Godoy, H.2005. Linfoadenitis Caseosa (LAC) en ovinos en la XI Región, Chile. Arch. Med. Vet. vol.37, n.2

Vadillo, S, S Píriz y E Mateos.2002. Manual de microbiología veterinaria. Madrid: McGraw -Hill Interamericana, 45-53pp.

Velasco, M y A Yamisaki.2009. "Bacterias de interés veterinario." MED. Vet. 19: 1-11.

Weese, J S.2002. "A Review of Equine Zoonotic Diseases: Risks in Veterinary Medicine." Proceedings of the Annual Convention of the AAEP 48 : 362-69.

White, S. D., A. A. Yu.2006. "Equine Dermatology." Proceedings of the annual convention of the AAEP 52 : 456-500.

White, S. D.2005."Equine Bacterial and Fungal Diseases: A Diagnostic and Therapeutic Update." Clinical Techniques in Equine Practice 4 : 302-10. 
Sustainability, Agri, Food and Environmental Research 3(4), 2015: 30-53

ISSN: 0719-3726

Zubrod C. J., Farnsworth K. D., Oaks J. L. 2004. "Evaluation of Arthrocentesis Site Bacterial Flora before and after 4 Methods of Preparation in Horses with and without Evidence of Skin Contamination". Veterinary Surgery 33:525-30. 